NBER WORKING PAPER SERIES

\title{
MULTI-ISSUE BARGAINING AND LINKED AGENDAS: RICARDO REVISITED OR NO PAIN NO GAIN
}

\author{
Ignatius J. Horstmann \\ James R. Markusen \\ Jack Robles \\ Working Paper 8347 \\ http://www.nber.org/papers/w8347
NATIONAL BUREAU OF ECONOMIC RESEARCH 1050 Massachusetts Avenue
Cambridge, MA 02138
June 2001

The authors thank participants in seminars at the Stockholm School of Economics, and ERWIT 2000 in Copenhagen for helpful comments and suggestions. The views expressed herein are those of the authors and not necessarily those of the National Bureau of Economic Research.

(C) 2001 by Ignatius J. Horstmann, James R. Markusen and Jack Robles. All rights reserved. Short sections of text, not to exceed two paragraphs, may be quoted without explicit permission provided that full credit, including (C) notice, is given to the source. 
Multi-Issue Bargaining and Linked Agendas:

Ricardo Revisited or No Pain No Gain

Ignatius J. Horstmann, James R. Markusen and Jack Robles

NBER Working Paper No. 8347

June 2001

JEL No. F02, F13, C78

\begin{abstract}
There has been much discussion about what issues should be included in international "trade" negotiations. Different countries, firms and activists groups have quite different views regarding which items should (or should not) be negotiated together. Proposals run the gamut from no linking to linking trade with investment, the environment, labor and human-rights codes. This paper provides a formal framework for analyzing these questions. It employs a two-country, two-issue bargaining model and contrasts outcomes when issues are negotiated separately and when they are linked in some form. A key concept is "comparative interest", analogous to Ricardian comparative advantage. We provide general results and note, in particular, where a country can benefit by agreeing to include an agenda item for which, when viewed by itself, the country does not receive a positive payoff.
\end{abstract}

Ignatius J. Horstmann

Department of Economics

University of Western Ontario

London, Ont. N6A 5C2

Canada

horstman@julian.uwo.ca

Jack Robles

Department of Economics

University of Colorado

Boulder CO 80309-0256

jack.robles@colorado.edu
James R. Markusen

Department of Economics

University of Colorado

Boulder, CO 80309-0256

and NBER

james.markusen@colorado.edu 


\section{INTRODUCTION}

Considerable controversy exists over what issues should and should not be included in multilateral trade negotiations. Some US and European groups, for example, want environmental and labor standards included with trade negotiations. Other groups from these same countries want to link trade with investment liberalization and intellectual-property protection. Some developing countries want competition policy included with any negotiations on investment liberalization. Not surprisingly, a linked negotiation desired by one group is often opposed by some other group; some writers oppose any linkage (especially trade with environment/labor standards) "on principle". The latter see any European or US attempt to link trade and environment in negotiations with developing countries as morally wrong and simply assume that the developing countries must be worse off with such a linkage (an assumption generally shared by those developing countries).

How is one is to assess the various arguments for and against linking? Two possible approaches suggest themselves as useful ways to analyze this issue formally. One is to investigate how treaties linking trade policies with other non-trade policy issues might (or might not) constrain non-cooperative policy-setting behavior more than would trade treaties alone. Much of the existing work on linked treaties takes this approach. The conclusions are decidedly mixed. Spagnolo (2000) argues that linking provides for more efficient enforcement of agreements by permitting more severe punishments for breaking the agreement. By contrast, Bagwell and Staiger (1999) argue that linking negotiations on trade with ones on domestic standards provides no benefits that can't be obtained without linking. Conconi and Perroni (2000) show that linking may help or hinder creation of a multilateral joint agreement on trade and the environment.

The alternative is to investigate how linking or not linking affects the actual treaty negotiation process and so the sorts of agreements that are (or are not) reached. Here, 
there are no formal analyses of the issues although Copeland and Taylor (1995) and Abrego et al. (1997) suggest potential benefits from linking trade and environmental treaties. It is this latter approach that we adopt in this paper, providing a bargainingtheoretic framework for understanding who gains and loses by linking issues. ${ }^{1}$ The framework that we employ is purposely simple, considering a situation in which there are two countries/trading blocs negotiating over two issues. The key distinguishing feature of the two issues is that one of them is more important to country 1 than to country 2 while the opposite is true for the other issue. This feature generates a pattern of "comparative interest" for the two countries in the two issues. This notion is analogous to Ricardian comparative advantage; it is somewhat more complicated in that negative payoffs from a given issue are an important part of the problem. With multiple issues, negotiations can involve either joint negotiations over both issues linking - or some form of separate negotiations on the issues - unlinking. We solve for the bargaining outcome in the linked setting versus various unlinked settings and examine which party gains (and which, if either, loses) from a given structure and on what this outcome depends.

Our analysis shows that a change in the bargaining structure from one in which issues are negotiated in isolation to one in which they are negotiated jointly generates gains for both countries under a wide range of circumstances. These include situations in which one country cannot receive a positive payoff from one issue. This result means that a country should not necessarily refuse to add an issue to the agenda just because it cannot receive any positive payoff from that issue when viewed in isolation. Adding this issue may allow the country to extract sufficient concessions from its negotiating partner on the other issue as to make the country better off overall. It is only if an issue yields the country an exceptionally large negative payoff,

\footnotetext{
${ }^{1}$ Our analysis draws on but also advances previous theoretical work on multiple issue bargaining (see especially, Busch and Horstmann $(1997,1999)$ and Inderst (2000)).
} 
when viewed in isolation, that it pays the country not to link issues.

The reason that both parties gain, in general, from linking in this situation is much the same as the reason that trade benefits both countries in a Ricardian trade model. Just as trade allows each country to exchange the good in which it has a comparative advantage for the good in which it does not, linking allows each country to trade concessions on the issue in which the country has a comparative disinterest for concessions from its opponent on the issue in which it has a comparative interest. This efficient trading of concessions is not possible if the issues are bargained independently. As a result, just as with Ricardian trade, both parties gain from this efficient trading process (via linking). Not linking only benefits a country if an issue yields a sufficiently large negative payoff. In this case, not linking provides the country with a credible commitment not to settle on this issue. This commitment is lost under linking.

We also examine an alternative notion of unlinked negotiations in which the countries bargain issues sequentially, not bargaining on the second issue until an agreement on the first has been reached and implemented. Under this notion of unlinking, an unlinked negotiation in which the issue that is bargained first is the one in which a country has a comparative interest can be preferred by that country to a linked negotiation. In this case, unlinking alters the relative bargaining costs of the two countries in a such a way that the one country gains even relative to the linked bargain. By contrast, the other country loses even in comparison to the completely separate negotiations. Among other things, this outcome points to the fact that, in discussing linking versus not linking, one must be careful to consider what exactly is meant by not linking.

These results carry a clear policy message. If the alternative to linked negotiations is simultaneous but separate negotiations, then countries can generally benefit from linking. In this case, it may well not pay a country to refuse to include an issue in negotiations simply because the country cannot receive a positive payoff from 
that issue (viewed in isolation). Inclusion of the issue allows for efficient trading of concessions that can benefit all parties. If the alternative to linking is sequentially separate negotiations - reach an agreement on trade first and only later negotiate agricultural subsidies or the environment - then not linking may well benefit a country if it can negotiate first on the issue in which it has a comparative interest. The country's negotiating partner should press for linked negotiations in this case.

In the remainder of the paper, we analyse these matters in detail. The specifics of the bargaining model are set out in the next section. Section 3 analyses the equilibrium for the cases of no linking and complete linking. Equilibria with sequential unlinking are analysed in Section 4. Section 5 provides applications of the analysis in two different trade settings. Section 6 concludes. Various proofs are collected in appendices.

\section{A STYLIZED MODEL OF NEGOTIATIONS}

Consider a situation in which there are two surpluses, $S_{1}$ and $S_{2}$, to be allocated between two individuals, 1 and 2 . The value of $S_{2}$ is normalized to 1 while the value of $S_{1}$ is assumed equal to $s$ with $s>0$. The utility functions for agents 1 and 2 are given by

$$
\begin{aligned}
& U_{1}=b_{1} s x+\left(1-c_{2}-y\right) \\
& U_{2}=\left(s-c_{1}-s x\right)+b_{2} y
\end{aligned}
$$

respectively, with $x \in[0,1]$ giving agent 1's share of $S_{1}$ and $y \in[0,1]$ giving agent 2's share of $S_{2}{ }^{2}$ The preference parameters $b_{1}, b_{2}$ give, respectively, agent 1 and 2's valuations of $S_{1}$ relative to $S_{2}$. It is assumed that $b_{1}, b_{2}>1$, implying that agent

\footnotetext{
${ }^{2}$ In these functions, units of measurement for $S_{1}$ and $S_{2}$ are also chosen so that 2's marginal utility from $S_{1}$ and 1's marginal utility from $S_{2}$ are both one.
} 
1's marginal utility from $S_{1}$ is greater than from $S_{2}$ (1 prefers $S_{1}$ to $S_{2}$ ) while the opposite is true for agent 2 (2 prefers $S_{2}$ to $S_{1}$ ). The parameters $c_{1}, c_{2} \geq 0$ represent costs of creating $S_{1}$ and $S_{2}$. It is assumed that agent $i$ bears the cost of creating the surplus that $i$ likes less (agent 1 bears the cost of creating $S_{2}$ and agent 2 the cost of creating $S_{1}$ ). The reason for this specification is twofold. First, it guarantees that, both on preference grounds and cost grounds, agent 1(2) prefers $S_{1}$ to $S_{2}\left(S_{2}\right.$ to $\left.S_{1}\right)$. Second, it allows for the possibility that agent 1 , for instance, might obtain negative utility from the creation of a positive utility for agent 2 . This outcome occurs if agent 2 gets more than the amount $1-c_{2}$ of $S_{2}$.

This specification is meant to capture several features of trade negotiations. First, in any negotiation, certain policies are more important to certain countries and less important to others. In the Canada/U.S. trade negotiations, for instance, Canada attached greater value to free trade than did the U.S.; the U.S., on the other hand, attached far greater value to reform of foreign investment rules than did Canada. Second, it's possible that a country can make a sufficient concession on same trade policy that, in the absence of any other changes, the country is worse off. ${ }^{3}$ Such is presumably the case for developing countries conceding to strong intellectual property protections under the WTO. The above specification captures both of these features and allows us to analyse the ways in which trade negotiations are affected by them.

Both objects are allocated via a bargaining process. Bargaining is modelled as a non-cooperative, alternating offers game a la Rubinstein (1982). Both agents know the values of $S_{1}$ and $S_{2}$ as well as the utility functions. Bargaining costs are modelled as delay costs, with each agent discounting the future at a common, known rate $\delta$. The equilibrium notion is subgame perfect Nash.

Because there are two surpluses to be divided, a complete specification of the

\footnotetext{
${ }^{3}$ Naturally, such a concession would only arise if the country in question were offered other concessions by its trading partners.
} 
game requires a specification of the bargaining agenda (the order in which issues are bargained) and a rule for implementing agreements. The agenda and implementation rule determine the sense in which issues are linked (or not linked). Initially, we consider linked an unlinked structures in their starkest forms. Specifically, the linked structure requires agents to bargain over the two surpluses together in the sense that an offer under the linked structure is a pair $[x, y]$ defining an allocation of both surpluses. All offers must be of this form and an offer must either be accepted in its entirety or rejected completely. An offer is implemented (allocations are made) as soon as it is accepted. Until an agreement is reached (or if no agreement is ever reached), the status quo point remains in effect with the utility for each agent normalized to zero in this case.

Under the unlinked structure the agents operate two bargaining games, one for the division of $S_{1}$ (game $G_{1}$ ) and one for the division of $S_{2}$ (game $G_{2}$ ) that are entirely separate in the sense that they operate simultaneously and there is no possibility of trade-offs across games. Formally, under the unlinked structure, an offer in $G_{1}$ is a value $x$ and an offer in $G_{2}$ is a value $y$. An offer in $G_{1}$ cannot be conditioned on the history in $G_{2}$ and vice versa; the same is true for an accept/reject decision. An agreement in either game is implemented as soon as it is reached in that game and independent of events in the other game. As with the linked structure, until an agreement is reached in a game (or if no agreement is ever reached) the status quo point remains in effect with the utility for each agent normalized to zero.

The sense in which these two structures represent the extremes forms of linked and unlinked bargaining structures is as follows. The linked structure permits the agents to fully exploit the benefits from trading-off concessions on their less preferred surplus for concessions by their opponent on the more preferred surplus. The trading of concessions cannot be limited by the agents making offers on only one of the objects or by accepting and implementing only part of an offer. The unlinked structure, by 
contrast, allows no trading of concessions (nor any exploitation of the benefits from so doing) as each surplus is bargained over separately and implemented separately.

In a subsequent section, we explore alternative notions of linking and unlinking issues involving bargaining structures that incorporate partial restrictions on the agents' abilities to trade concessions. These agendas allow linked bargaining but with partial offers (offers on only one of the two surpluses) that can be implemented immediately should they be accepted. We also discuss ways to interpret these different structures in terms of actual trade negotiations.

\begin{abstract}
ANALYSIS
In what follows, we first analyze the bargained outcome under the unlinked structure and then under the linked structure. Finally we compare the two and determine conditions under which linking is (or is not) Pareto improving. ${ }^{4}$
\end{abstract}

\title{
The Unlinked Bargaining Structure
}

The unlinked bargaining structure is equivalent to two separate Rubinstein bargaining games $\left(G_{1}\right.$ and $\left.G_{2}\right)$ with agent preferences in $G_{1}$ given by $U_{1}^{1}=b_{1} s x$ and $U_{2}^{1}=s-c_{1}-s x$ and those in $G_{2}$ given by $U_{1}^{2}=1-c_{2}-y$ and $U_{2}^{2}=b_{2} y$. It is well known that these games have unique subgame perfect equilibria and that, as $\delta \rightarrow 1$, the equilibrium utilities converge to the Nash bargaining solution over the

\footnotetext{
${ }^{4}$ The analysis here shares some similarities with work by Horn and Wolinsky (1988) and Jun (1989) in a labor union context. These papers examine whether two distinct sets of workers would prefer to bargain with a single employer as a joint union or two separate unions. Because each worker group only cares about wages to that group, joint versus separate negotiations comes down to a matter of how each structure affects a given groups threat point in bargaining. Here, by contrast, an agent's choice between linked and unlinked agendas comes down to the way that each agenda allows trade-offs across issues and how each affects an agent's bargaining costs.
} 
utility frontier for the given game. To facilitate comparisons between utilities under the linked and unlinked structures, we study only these limiting equilibria and the corresponding utilities implied by the appropriate Nash bargaining solution.

For the bargaining game $G_{1}$, the Nash bargaining solution is defined by

$$
\begin{array}{ll} 
& \max _{u_{1}^{1}, u_{2}^{1}} U_{1}^{1} U_{2}^{1} \\
\text { s.t. } U_{1}^{1}= & s b_{1}-b_{1}\left(U_{2}^{1}+c_{1}\right) .
\end{array}
$$

Similarly, for $G_{2}$, the Nash bargaining solution is

$$
\begin{array}{cc} 
& \max _{u_{1}^{2}, u_{2}^{2}} U_{1}^{2} U_{2}^{2} \\
\text { s.t. } U_{2}^{2}= & b_{2}-b_{2}\left(U_{1}^{2}+c_{2}\right) .
\end{array}
$$

The frontiers for these problems are represented in Figure 1 for the case $c_{1}=c_{2}=0$ and in Figure 2 for $c_{1}>s, c_{2}>1$.

In the bargain over $S_{1}$, the limiting SPE yields utility for agent 1 of $U_{1}^{1}=\max \left[0, \frac{b_{1}\left(s-c_{1}\right)}{2}\right]$ and utility for agent 2 of $U_{2}^{1}=\max \left[0, \frac{s-c_{1}}{2}\right]$. The reader can check that these are utilities implied by the Nash bargaining solution in (3) above. In the bargain over $S_{2}$, the limiting allocation yields utilities of $U_{1}^{2}=\max \left[0, \frac{1-c_{2}}{2}\right]$ and $U_{2}^{2}=\max \left[0, \frac{b_{2}\left(1-c_{2}\right)}{2}\right]$. Again, these are the utilities from the Nash bargaining solution in (4) above. If $c_{1} \leq s$ and $c_{2} \leq 1$, then total utility for agent 1 under the unlinked agenda is then $U_{1}^{1}+U_{1}^{2} \equiv$ $U_{1}^{u}=\left(s b_{1}-b_{1} c_{1}+1-c_{2}\right) / 2$ and for agent 2 it is $U_{2}^{1}+U_{2}^{2} \equiv U_{2}^{u}=\left(b_{2}-b_{2} c_{2}+s-c_{1}\right) / 2$. Utility for the other cost configurations can be derived similarly.

\section{The Linked Structure and the Gains from Linking}

Under the linked bargaining structure it can be shown that the bargaining game is equivalent to one in which each player's offer is a utility pair drawn from the utility 
possibility frontier, $\mathcal{U}_{L}$. This frontier is defined by the problem

$$
\begin{aligned}
& \max _{x, y} U_{1}=b_{1} s x+1-c_{2}-y \\
& \text { s.t. } U_{2}=s-c_{1}-s x+b_{2} y=\bar{U},
\end{aligned}
$$

and is illustrated in Figure 3 for the case $c_{1}, c_{2}=0$ and in Figure 4 for the case $c_{1}, c_{2} \neq 0$. The linked bargaining game has a unique SPE whose limiting value as $\delta \rightarrow 1$ is the Nash bargaining solution over $\mathcal{U}_{L}$.

Because the utility frontier for $S_{1}$ is everywhere steeper than that for $S_{2}$, a point on $\mathcal{U}_{L}$ must have at least one agent obtaining all of the surplus preferred by that agent (i.e., either agent 1 must at least have all of $S_{1}$ or agent 2 at least have all of $S_{2}$ ). When both surpluses allocated under the unlinked structure (which occurs if $s>c_{1}$ and $1>c_{2}$ ), neither agent obtains all of either surplus. As a result, the utility point under the unlinked structure must be strictly inside the utility frontier. In this case the linked bargain must make at least one of the agents better off. The only question, then, is whether both are made better off. The following proposition provides conditions under which both agents are strictly better off from linking. The proof of the proposition is in the Appendix.

Proposition 1 If $s>c_{1}>0$ and $1>c_{2}>0$, then the linked bargain yields strictly higher utility for both agents relative to the unlinked bargain.

This result is illustrated in Figure 4 below.

Several points about this result are worth noting. First, it's important for the result that $b_{1}, b_{2} \neq 1$; that is, it's important that the agents have comparative interests in different surpluses. Were $b_{1}, b_{2}=1$, then the unlinked bargain would also give a point on the $\mathcal{U}_{L}$. Specifically, it would give the point $U_{1}=U_{2}=\left(1+s-c_{2}-c_{1}\right) / 2$. Since the slope of the utility frontier is 1 in this case, the linked and unlinked bargains 
give the same outcome. That $b_{1}, b_{2} \neq 1$ (there are differing interests) means that the unlinked bargain puts the agents strictly interior to the utility space of the linked bargain. In this case, linking produces utility gains for both agents by allowing an efficient allocation of the goods (as long as the transfer costs are not too large).

In a similar vein, it is important that $c_{1}, c_{2} \neq 0$. Positive costs mean that the unlinked bargain produces an additional misallocation due to agent $i$ having to give $j$ some of the surplus that $i$ prefers simply to induce $j$ to participate at all in the unlinked bargain. More concretely, consider the bargain over $S_{2}$ in the unlinked case. In this bargain, agent 1 has zero cost of making a counteroffer unless he obtains at least $c_{2}$ units of $S_{2}$. This fact gives 1 extra bargaining power (relative to the case in which $\left.c_{1}=0\right)$ and so 1 extracts more $S_{2}$ (the good that 2 prefers). The linked agenda allows 2 to compensate 1 for the cost $c_{2}$ through $S_{1}$ (and similarly allows 1 to compensate 2 for $c_{1}$ through $S_{2}$ ) and so provides an additional efficiency gain.

To see the importance of positive costs, suppose that at least one of $c_{1}, c_{2}$ is 0 . As the following proposition shows, in this case it's possible that only one of the agents is made strictly better off by linking (the other will be indifferent). ${ }^{5}$

Proposition 2 If $c_{2}=0$ and $s>b_{2}-c_{1}$ then agent 1's utility strictly increases under the linked bargain while agent 2's utility is unchanged; if $c_{1}=0$ and $1>s b_{1}-c_{2}$ then 2's utility strictly increases while 1's utility is unchanged.

An implication of this proposition is that, if $S_{1}$ is small enough (see Figure 7) then 2 extracts all of the gains from linking even when $c_{1}=c_{2}=0$; similarly, if $S_{1}$ is large enough, 1 extracts all of the gains from linking even when both costs are zero. This result is illustrated in Figure 8 for the case in which agent 2 captures all of the surplus. The reader can easily check that, for $S_{1}=1$, both agents must gain from linking when $c_{1}=c_{2}=0$.

\footnotetext{
${ }^{5}$ This result is a generalization of a result in Inderst (2000).
} 
To see the intuition for this result, consider the case of $c_{1}=c_{2}=0$. In this case, the unlinked bargain produces an inefficient outcome because it allocates some of both objects to both agents. In general, this bargain provides too little of $S_{1}$ to agent 1 and too little of $S_{2}$ to agent 2. When $S_{1}$ is small, though, this is not the case in the following sense: agent 1's utility in the unlinked bargain can be achieved through an efficient allocation in the linked bargain by giving 1 all of $S_{1}$ and some share of $S_{2}$ (this is the essence of the condition on $c_{2}$ in the proposition). In terms of utility, then, agent 1 is not under allocated $S_{1}$ in the unlinked bargain; only $S_{2}$ is under allocated to agent 2. As a result, the efficiency gains from linking are purely in terms of correcting the under allocation of $S_{2}$ to agent 2; effectively, agent 1 obtains no efficiency benefits from linking. For this reason, 2 obtains all of the gains from linking.

By contrast, when $S_{1}=1$, the utilities under the unlinked bargain can only be achieved under the linked bargain if both agent 1 obtains less than all of $S_{1}$ and agent 2 obtains less than all of $S_{2}$. In this case, both goods are under allocated to both agents. As a consequence, both agents have efficiency benefits from linking and both agents' utilities increase in the linked game. ${ }^{6}$

\footnotetext{
${ }^{6}$ Another way to look at this result is the following: 1) Efficient allocation of goods requires that agent 1 only be allocated a share of $S_{2}$ if 2 obtains none of $S_{1}$ and that agent 2 only be allocated a share of $S_{1}$ if 1 obtains none of $S_{2}$. 2) Any interior point in the utility space $\mathcal{U}_{L}$ can be thought of as equivalent to an allocation in which this efficient rule is followed but some of either $S_{1}$ or $S_{2}$ (or both) is not allocated. In particular, we can think of the utility levels under the unlinked bargain in this fashion. 3) The notion of small here is that, for agent 1 to obtain utility under the linked bargain equal to that under the unlinked bargain, 1 must obtain all of $S_{1}$ and some share of $S_{2}$ (this is the essence of the condition on $c_{2}$ in the proposition). The implication of point 3 is that, when $S_{1}$ is small, the unlinked bargain yields 1 a utility point in $\mathcal{U}_{L}$ that can only be equivalent to efficient rule allocations (point 2) in which all of $S_{1}$ is allocated. Some of $S_{2}$ is not allocated only to achieve agent 2's utility outcome from the unlinked bargain. In this sense, the inefficiency in the unlinked bargain falls fully on agent 2 and so all of the efficiency gains from linking accrue to agent 2 through
} 
A corollary of Propositions 1 and 2 is that, as long as $c_{1}, c_{2}$ are not too large, neither agent is made worse off by using the linked bargain. Specifically,

Corollary 1 If $s>c_{1} \geq 0$ and $1>c_{2} \geq 0$, then neither agent is worse off under the linked bargain than under the unlinked bargain.

When the costs of creating a given surplus are large $\left(c_{1}>s\right.$ and/or $\left.c_{2}>1\right)$, the linked structure may no longer be preferred by both agents to the unlinked one. To see the reason, consider the situation in which that $c_{2}>1$ while $c_{1}<s$. In this case the unlinked structure results in $S_{2}$ not being allocated, with a cost saving to agent 1 of $c_{2}$. With the linked structure agent 1 gives up the ability to refuse to allocate $S_{2}$. While agent 1 can be compensated for $c_{2}$ through a larger share of $S_{1}$ in the linked structure (the benefit of the linked structure over the unlinked one), $c_{2}$ may be sufficiently large that agent 1 is still made worse off by linking. The following proposition defines conditions under which such is the case. ${ }^{7}$

Proposition 3 Suppose that $c_{2}>1$ and $0<c_{1}<s<2 c_{2} / b_{1}-c_{1}$. If, in addition, $c_{1}\left(b_{1}-1 / b_{2}\right)<c_{2}-1<.5\left(s+c_{1}\right)\left(b_{1}-1 / b_{2}\right)$, then agent 1 prefers the unlinked structure to the linked while agent 2 prefers the linked structure to the unlinked.

The situation described in the proposition is depicted in Figure 10. Note in the figure that the utility frontier for the linked structure intersects the $U_{1}$-axis below the intersection point of the utility frontier for the unlinked structure. This outcome is the implication of the condition $c_{1}\left(b_{1}-1 / b_{2}\right)<c_{2}-1$ and means that, as measured by the maximum payoff attainable by agent 1, linking is detrimental to 1 . Note also that the efficient allocation of $S_{2}$. Because of this fact, agent 2 captures all of the efficiency gains.

By contrast, when $c_{1}=c_{2}=0$ and $S_{1}=1$, the unlinked bargain utility levels are equivalent to efficient rule allocations in which some of both $S_{1}$ and $S_{2}$ are not allocated. As a result, both agents bear the efficiency costs of not linking and so both captures some of the efficiency gains from linking.

${ }^{7}$ An analogous result can be derived for linking making agent 2 worse off. 
the utility pair under the unlinked structure lies inside the utility frontier of the linked structure. Under the assumption that $s$ is small relative to $c_{2}\left(s<2 c_{2} / b_{1}-c_{1}\right)$, this utility outcome is implied by the condition $c_{2}-1<.5\left(s+c_{1}\right)\left(b_{1}-1 / b_{2}\right)$ and means that at least one of the agents must gain from linking. Combined, these three conditions mean that the bargaining solution for the linked structure yields agent 1 less utility and agent 2 more utility than under the unlinked structure. Intuitively, what happens in this case is that $s$ is sufficiently small relative to $c_{2}$ that the linked structure can provide agent 1 with the same utility level as the unlinked structure only if linking allocates all of $S_{1}$ and some share of $S_{2}$ to agent 1 . As in the previous proposition, the only gain to linking for 1 in this case is that he can efficiently compensate agent 2 for $c_{1}$ through $S_{2}$. This efficiency gain is given by the expression $c_{1}\left(b_{1}-1 / b_{2}\right)$. The gross surplus that 1 loses from linking is given by $1-c_{2}$. With $1-c_{2}+c_{1}\left(b_{1}-1 / b_{2}\right)<0$, agent 1 loses from linking.

Basically, in situations such as the above (i.e., $c_{2}$ large), unlinking provides agent 1 with a credible commitment not to allocate $S_{2}$ by allowing 1 to delay agreement on $S_{2}$ indefinitely. By linking, agent 1 gives up this commitment in that delaying agreement indefinitely delays agreement on both surpluses. The result is that, in spite of the efficiency gains from linking, agent 1 can be made worse off by the linked structure. ${ }^{8}$ This outcome occurs when the issue in which agent 1 has a comparative interest is small relative to the cost associated with the issue in which 1 has a comparative disinterest.

\section{AN ALTERNATIVE UNLINKED STRUCTURE}

As noted earlier, the two bargaining structures above place linked and unlinked bargaining in particularly stark contrast. Unlinked bargaining allows no efficient trade-off

\footnotetext{
${ }^{8}$ The reader should note that $c_{2}>1$ is not sufficient for linking to make agent 1 worse off. Figure 9 provides an example in which 1 gains even though $c_{2}>1$.
} 
of surpluses while linked bargaining permits full exploitation of such trade-offs. Other bargaining structures are possible, even in this simple setting, that permit alternative characterizations of linked/unlinked bargaining. We examine these structures here and provide a comparison with the above results on the gains from linking. ${ }^{9}$

The additional bargaining structures available in this setting are ones in which issues can be bargained sequentially and implementation of an agreement on one issue linked in various ways to whether or not agreement has been reached on the other issue. Essentially, three additional structures are available: 1) The agents bargain only on $S_{1}$ and once agreement has been reached on $S_{1}$ bargain on $S_{2}$. The agreement on $S_{1}$ is binding (in the sense that it can't later be re-opened) and is implemented at a fixed date whether or not agreement is ever reached on $S_{2}$. 2) The agents bargain only on $S_{2}$ and once agreement has been reached on $S_{2}$ bargain on $S_{1}$. The agreement on $S_{2}$ is binding (in the sense that it can't later be re-opened) and is implemented at a fixed date whether or not agreement is ever reached on $S_{1}$. 3) The agents bargain only on $S_{1}\left(S_{2}\right)$ and once agreement is reached on that surplus bargain on $S_{2}\left(S_{1}\right)$. The agreement on $S_{1}\left(S_{2}\right)$ is binding but is only implemented once agreement has been reached on $S_{2}\left(S_{1}\right)$. Fershtman (1990) has shown that, unless the two surpluses are of very different sizes, procedure 3 generates the same outcome as the linked bargain as $\delta \rightarrow 1$. In this case, then, there are basically two other structures ( 1 and 2 above), each with a sequential (implement as agreement is reached) implementation rule.

These two structures provide an alternative notion of unlinked bargaining (In what follows, we refer to these structures as sequentially unlinked structures.). In particular, the issues are unlinked in two senses. First, implementation of any agreement on the first issue is independent of whether or not agreement is ever reached on the second issue. This is as in the unlinked structure above and in contrast to the linked

\footnotetext{
${ }^{9}$ The analysis in this section draws heavily on previous work by Busch and Horstmann.
} 
structure. Second, because of this implementation rule, bargaining on the second issue is unaffected by any agreement on the first. Again, this is as in the unlinked structure above. This structure is different from the unlinked structure above because bargaining on the second issue only commences once agreement has been reached on the first. As a result, the bargained outcome on the first issue depends on the agreement that will be reached on the second issue. This fact means that there is some scope for efficient trade-offs under this structure not available under the above unlinked structure. As a result, these sequentially unlinked structures yield different outcomes from the previous unlinked structure.

Under this sequential notion, unlinked trade negotiations are ones that delay negotiation on certain issues until agreements on others have been reached. For instance, negotiations on agricultural subsidies are delayed until agreement has already been reached on intellectual property issues. Alternatively, negotiations on environmental issues are delayed until agreement had been reached on free trade. What are the benefits of structuring negotiations in this way?

To answer this question we need to determine the bargained outcome under the sequential structure and compare utilities to those under the linked an unlinked structures? To get some sense of the comparisons, consider the case in which $c_{1}=c_{2}=0$. Consider first the structure $S_{1}$ then $S_{2}$. Once agreement is reached on $S_{1}$, the bargain on $S_{2}$ has no impact on the utility that agents receive from the $S_{1}$ agreement: the agreement is binding and the allocation of $S_{1}$ is made upon agreement. As a result, the bargain on $S_{2}$ is as under the unlinked structure, with the limiting allocation being $y=1 / 2$ and the limiting utilities from $S_{2}$ being $U_{1}=1 / 2, U_{2}=b_{2} / 2$.

The bargain on $S_{1}$ is different from the unlinked structure since bargaining is sequential rather than simultaneous: bargaining doesn't begin on $S_{2}$ until agreement is reached on $S_{1}$. The sequential structure of bargaining is important because failure to reach agreement on $S_{1}$ delays agreement on (and consumption of) $S_{2}$. Thus, 
both agents bear a utility cost from continued bargaining on $S_{1}$ that reflects both their valuations of $S_{1}$ and $S_{2}$. Under the unlinked structure, because bargaining is simultaneous, the utility cost of continued bargaining on $S_{1}$ reflects only the agents' valuations of $S_{1}$. Formally, letting $\left(x_{s}^{*}, x_{s}^{* *}\right)$ be the offers on $S_{1}$ by agents 1 and 2 respectively in this sequential game, the conditions defining equilibrium are: ${ }^{10}$

$$
\begin{aligned}
s\left(1-x_{s}^{*}\right) & =s\left(1-x_{s}^{* *}\right)-(1-\delta)\left[s\left(1-x_{s}^{* *}\right)+\delta b_{2}\right) \\
b_{1} s x_{s}^{* *} & =b_{1} s x_{s}^{*}-(1-\delta)\left(b_{1} s x_{s}^{*}+\delta\right) .
\end{aligned}
$$

Bargaining costs for this agenda are $(1-\delta)\left[\left(s\left(1-x_{s}^{* *}\right)+\delta b_{2}\right)\right.$ for agent 2 and $(1-$ $\delta)\left(b_{1} s x_{s}^{*}+\delta\right)$ for agent 1 . By contrast, under an unlinked structure, bargaining costs would be $(1-\delta) s\left(1-x^{* *}\right)$ and $(1-\delta) b_{1} s x^{*}$ for 2 and 1 respectively.

As before, the limiting equilibrium is given by an appropriately defined Nash bargaining solution. From the above, this solution is given by the condition

$$
b_{1} \geq \frac{b_{1} x_{s}+1}{s\left(1-x_{s}\right)+b_{2}},
$$

where the inequality allows for the fact that the solution may be a corner solution in which $x_{s}=1$. Indeed, if $b_{2}>s+\frac{1}{b_{1}}$, the outcome is a corner solution. In this case,

\footnotetext{
${ }^{10}$ The structure of offers and counteroffers assumed here is that, if bargaining on $S_{1}$ ends with agent 1 accepting an offer from agent 2 , then agent 1 makes the first offer on $S_{2}$. Similarly, if bargaining on $S_{1}$ ends with 2 accepting an offer from 1 , then 2 makes the first offer on $S_{2}$. This means that the conditions for an equilibrium are:

$$
\begin{aligned}
1-x^{*}+\delta b_{2} /(1+\delta) & =\delta\left[1-x^{* *}+\delta^{2} b_{2} /(1+\delta)\right] \\
b_{1} x^{* *}+\delta /(1+\delta) & =\delta\left[b_{1} x^{*}+\delta^{2} /(1+\delta)\right],
\end{aligned}
$$

where we've used the fact that the offer 1 makes on $S_{2}$ gives 2 the share $\delta /(1+\delta)$ and the share demand that 2 makes gives $21 /(1+\delta)$.
} 
the utility allocation is a point on the frontier of the utility possibility set, $\mathcal{U}_{L}$, with $U_{1}^{s 1}=s b_{1}+.5, U_{2}^{s 1}=.5 b_{2}$.

How does this outcome compare to that of the linked and unlinked structures? For this case, the linked structure outcome has agent 1 getting all of $S_{1}$ and agent 2 all of $S_{2}$, yielding utilities $U_{1}^{l}=s b_{1}, U_{2}^{l}=b_{2}$. The unlinked structure gives utilities $U_{1}^{u}=.5 s b_{1}+.5, U_{2}^{u}=.5 b_{2}+.5 s$. Clearly, agent 1 prefers the sequentially unlinked structure to the linked structure $\left(U_{1}^{s 1}>U_{1}^{l}>U_{1}^{u}\right)$ while agent 2 finds the sequentially unlinked structure worst of all $\left(U_{2}^{s 1}<U_{2}^{u}<U_{2}^{l}\right)$.

A similar analysis can be performed for the structure $S_{2}$ then $S_{1}$. As long as $b_{1}>\frac{1}{s}+\frac{1}{b_{2}}$, the outcome again will be on the utility frontier with agent 2 getting all of $S_{2}$ and half of $S_{1}$. The utilities for the two agents for this structure are $U_{1}^{s 2}=$ $.5 s b_{1}, U_{2}^{s 2}=b_{2}+.5 s$. In this case, agent 2 prefers this sequentially unlinked structure to all others while agent 1 finds this structure worse than even the unlinked structure. So we have

Proposition 4 Suppose that i) $c_{1}=c_{2}=0$ and ii) $b_{1}>\frac{1}{s}+\frac{1}{b_{2}}, b_{2}>s+\frac{1}{b_{1}}$, then agent 1(2) prefers the sequentially unlinked structure $S_{1}$ then $S_{2}\left(S_{2}\right.$ then $\left.S_{1}\right)$ to all other bargaining structures. Agent 2(1) finds the sequentially unlinked structure $S_{1}$ then $S_{2}\left(S_{2}\right.$ then $\left.S_{1}\right)$ worse than the unlinked structure.

The intuition for this result can be found in the way that the various structures affect the agents' relative bargaining costs. Under the linked structure, agent 1 finds it costly to hold out for a positive share of $S_{2}$ since doing so delays agreement on (and consumption of) $S_{1}$, the surplus 1 prefers. Similarly, 2 finds it costly to hold out for a positive share of $S_{1}$ since doing so delays agreement on (and consumption of) $S_{2}$, the surplus 2 prefers. The result is that each agent obtains all of the surplus that that agent prefers and none of the other surplus.

In the sequentially unlinked structure $S_{1}$ then $S_{2}, 1$ has already obtained his al- 
location of $S_{1}$ before bargaining on $S_{2}$ begins. As a result, it is now cheap for 1 to hold out for a share of $S_{2}$ since doing so doesn't delay consumption of $S_{1}$. In essence, 1's bargaining costs on $S_{2}$ are now low relative to 2's and so 1 obtains a positive share of $S_{2}$. In the prior bargain over $S_{1}$, the agents' relative bargaining costs are not much changed from the linked bargain: it's relatively costly for 1 to concede some of $S_{1}$ since this surplus is the one that 1 prefers and 2's holding out for a large share of $S_{1}$ continues to delay agreement on $S_{2}$. Overall, then, the sequentially unlinked agenda $S_{1}$ then $S_{2}$ lowers 1's bargaining costs relative to 2's and so puts one in a favorable bargaining position relative to the linked structure. Two is damaged both relative to the linked structure and the unlinked structure since 2 continues to concede on $S_{1}$ because not doing so delays agreement on $S_{2}$ (which is not so in the unlinked structure). Analogous arguments explain 2's preference (and 1's dislike) for the structure $S_{2}$ then $S_{1}$.

When $c_{1}, c_{2}>0$, the sequentially unlinked structure inherits some of the same inefficiency properties that the unlinked structure has. Specifically, an agent is compensated for the cost of creating a given surplus directly from that surplus rather than indirectly from the surplus that the agent prefers more. If costs are large enough, this inefficiency can reverse the above rankings. Just as an example, if $c_{2} \geq 1$, then the sequentially unlinked structure in which $S_{1}$ is bargained first yields exactly the same allocation as the unlinked structure. The same is true of the sequential structure in which $S_{2}$ is bargained first when $c_{1} \geq s$. As has already been seen, in such cases the linked structure can dominate the unlinked structure and as a result, various sequentially unlinked structures. ${ }^{11}$

\footnotetext{
${ }^{11}$ As an example, consider the case of $c_{2}=1$ and $c_{1}=s$, with $s=1$. Here linking benefits both parties. See also Figure 11.
} 


\section{DISCUSSION AND APPLICATIONS}

There are three basic messages contained in the above analysis: i) a linked structure permits agents to make efficient trades across issues not available in an unlinked structure. As a result, when both agents wish to settle both issue, there are gains to both from linking. ii) When some agent can never benefit directly from settling an issue, unlinking provides that agent a credible means of committing to not settling the issue. This credible commitment is unavailable under linking and so unlinking can (although need not) make that agent better off. iii) Sequential unlinking alters the relative bargaining costs of the agents, with an agent benefitting by bargaining first over his preferred issue. This change in bargaining cost can result in an agent preferring sequential unlinking to linking.

While we believe the above insights apply in quite general settings, we have, in fact, proven their relevance only for a highly stylized bargaining model. As a consequence, we think it is useful at this point to explore the extent to which our stylized model applies directly in a trade setting. Doing so allows us not only to demonstrate the relevance of even this stylized model but also to understand what are fruitful directions for generalizing the model (and so the results).

Two features of our stylized model seem potentially problematic for economic applications. One is that utility frontiers are linear/piecewise linear. Typically, analyses of economic policy questions don't assume transferable utility and so won't result in linear utility frontiers. The other is that there is strong independence across issues in the sense that the allocation of one surplus affects neither the size nor an agent's evaluation of the other surplus. Such independence seems an unlikely possibility, especially in general equilibrium settings.

Of the two, the former seems less important, in the sense that linearity of the frontiers is only relevant to the extent that it guarantees that one frontier is every- 
where steeper than the other. As long as this assumption is satisfied, whether the frontiers are linear or non-linear is inconsequential to the results of our analysis. The independence assumption is a much stronger restriction and, as will be seen below, imposes significant limitations on the sorts of models that can satisfy it. In what follows, we provide two models that satisfy both assumptions. The first is a trade and environment model, the second a trade and foreign investment model.

\section{Trade and the Environment}

The model here is motivated by the trade and environment model of Copeland and Taylor (1995). ${ }^{12}$ The trade side of the model is a standard Heckscher-Ohlin model, with two goods ( $X$ and $Y$ ), two factors $(K$ and $L)$ and two countries $(1$ and 2$)$. Country 1 (e.g., US) exports $X$ and is large relative to country 2 (e.g., Mexico). The initial equilibrium is tariff ridden, with each country having identical tariffs against imports from the other country. The trade policy to be negotiated is a mutual tariff reduction of some amount (reciprocal trade enhancement).

As for the environmental side, it is assumed that consumption (and not production) activities create pollution that spills over to the other country. For simplicity, we assume specifically that pollution flows from Country 2 to Country 1 but not vice versa (e.g., wind blows or water flows from South to North). Disutility of pollution is additively separable from consumption (as in Copeland and Taylor). A pollution abatement technology exists in Country 2. This technology is identical to the "consumption technology" (national utility function) in the sense that it uses goods (or indirectly factors) in the same proportions as consumption. The cost of pollution abatement is borne solely by Country 2 and is financed by a proportionate consumption tax. ${ }^{13}$ It is assumed that the benefit to Country 2 from abatement is sufficiently

\footnotetext{
${ }^{12}$ We thank Scott Taylor for suggesting this application.

${ }^{13}$ There are two relevant assumptions here. One is that pollution abatement essentially involves
} 
small that the initial situation is one in which Country 2 does no abatement. The environmental policy to be negotiated is a level of pollution abatement, defined here as the amount of measurable inputs allocated to abatement by Country 2 .

It can be checked that this model satisfies the independence assumptions of our stylized bargaining model. Key to this outcome are the assumptions that the disutility of pollution is additively separable from the utility of consumption and that the abatement technology is identical to the consumption technology. The latter guarantees that the abatement activity has no consequences for general equilibrium prices and demands and so no impact on the benefits from trade liberalization. Increased abatement activity just shifts consumption demand between the private and public sectors. The former guarantees that the trade regime has no impact on the benefits from pollution reduction. The cost of pollution reduction is just the foregone consumption in Country 2, the amount of which is independent of the trade regime.

Figure 11 provides the relevant utility frontiers for a situation in which Country 1 is ten times the size of Country 2 and the initial tariff level in both countries is $50 \%$. Note that the example is such that Country 2 never gains from pollution abatement while Country 1 never gains from mutual tariff reductions. As a consequence both the unlinked bargain and the sequentially unlinked bargain implement the status quo point (no change in tariffs and no abatement). The linked bargain implements free trade and abatement of pollution by Country 2. Both countries are better off under the linked structure than at the status quo point and so better off than under any unlinked structure.

the government of Country 2 shifting some consumption from private to public consumption (abatement). The other is that the government of Country 1 cannot commit to paying for Country 2 pollution abatement directly. 


\section{Trade and Investment rules}

The second model is a standard trade model with imperfect competition. It is assumed that there are 2 countries ( 1 and 2$), 3$ goods $(X, Y$, and $Z)$ and 1 factor $(L)$. Good $Z$ is the numeraire and is produced in a perfectly competitive industry with a constant returns to scale technology such that 1 unit of $Z$ requires 1 unit of $L$. Goods $X$ and $Y$ are produced in both countries under conditions of imperfect competition, with fixed cost/constant marginal cost production technologies. Markets for both goods are segmented internationally (there is international price discrimination) and there is Cournot competition in all markets. The numbers of firms in each country and in each market are fixed exogenously. Consumers in both countries have identical preferences given by the utility function $U=c_{z}+a c_{x}-(b / 2) c_{x}^{2}+d c_{y}-(e / 2) c_{y}^{2}$, where $c_{j}$ is the consumption of good $j$. These preferences imply that demands for both $X$ and $Y$ are linear demands and depend only on their own prices.

In the $X$ market, it is assumed that there is a common tariff set by both countries and the trade negotiation is on a mutual tariff reduction. In the $Y$ market, country 1 provides production subsidies for domestic producers but no subsidy for a foreign branch plant. Country 2 has no subsidies for either domestic or foreign production. The foreign investment negotiation is over policy of subsidy removal/reduction for domestic producers in country 1.

Again, one can check that this model satisfies the independence assumption of our bargaining model. In this case, independence comes from the additive separability of preferences and the assumption that there are no general equilibrium effects in the factor market (the price of $L$ is always 1 ). 


\section{SUMMARY AND CONCLUSIONS}

In this paper we have explored the potential benefits (and costs) of linking agreements on trade with agreements on other, non-trade issues. Our analysis suggests that linking may well be a virtue rather than a vice. By linking, a country can extract concessions from its negotiating partners on an issue of importance to that country in exchange for concessions on issues of importance to its partners. This efficient trading of concessions can be beneficial to a country even in circumstances in which the linked issue, when viewed in isolation, has negative marginal value to the country.

The U.S.-Canada free trade negotiations and later the NAFTA negotiations may provide an example of just this point. The U.S. wanted to provide tough provisions on services and investment while Canada preferred to stick with goods only. If Canada and Mexico had not agreed to include services and investment, our guess is that the negotiations would have failed since there was little support (rightly or wrongly) in the U.S. for trade in goods, especially with Mexico. By agreeing to include issues in which Mexico and Canada perceived (rightly or wrongly) that they had nothing to gain, these two countries improved their welfare through trade concessions that were worth more than what they gave up on services and investment.

When linking is not beneficial to a country it is either because the linked issue has very large (relative to other issues) negative value or because the country can gain by bargaining issues sequentially. In this latter case, sequential bargaining beginning with the issue of importance to the country alters relative bargaining costs in a way that makes the country better off. This result may explain why the EU wishes to delay negotiations on agriculture or why developing countries prefer to delay environmental agreements until after agreements on free trade have been reached.

We note in closing that an unanswered question here is how the bargaining struc- 
ture is determined. One possible answer is that it too is subject to negotiation. ${ }^{14}$ Alternatively, it may be that these structures have been institutionalized through various international arrangements or organizations. In this case, the analysis above will be useful for understanding these institutions and for determining who gains and loses from them. These matters are the subject of on-going research.

\footnotetext{
${ }^{14}$ This is the approach taken in Busch and Horstmann (1999).
} 


\section{REFERENCES}

[1] Abrego, L.E., C. Perroni, J. Whalley and R. Wigle (1997), "Trade and Environment: Bargaining Outcomes from Linked Negotiations", NBER Working Paper 6216.

[2] Bagwell, K. and R. Staiger (1999), "Domestic Policies, National Sovereignty and International Economic Institutions", mimeo.

[3] Busch, L.-A. and I. Horstmann (1997), "Bargaining Frictions, Bargaining Procedures and Implied Costs in Multiple-Issue Bargaining", Economica 64, 669-80.

[4] ________ (1999), "Endogenous Incomplete Contracts: A Bargaining Approach", Canadian Journal of Economics 32, 956-75.

[5] Conconi, P. and C. Perroni (2000), "Issue Linkage and Issue Tie-In in Multilateral Negotiations", mimeo.

[6] Copeland, B. and S. Taylor (1995), "Trade and Transboundary Pollution", American Economic Review 85, 716-37.

[7] Fershtman, C. (1990), "The Importance of the Agenda in Bargaining", Games and Economic Behavior 2, 224-38.

[8] Horn, H. and A. Wolinsky (1988), "Worker Substitutability and Patterns of Unionisation", Economic Journal 98, 484-97.

[9] Inderst, R. (2000), "Multi-Issue Bargaining with Endogenous Agenda", Games and Economic Behavior 30, 64-82.

[10] Jun, B. H. (1989), "Non-Cooperative Bargaining and Union Formation", Review of Economic Studies 56, 59-76.

[11] Nash, J. (1950), "The Bargaining Problem", Econometrica 18, 155-62. 
[12] Rubinstein, A. (1982), "Perfect Equilibrium in a Bargaining Model", Econometrica $50,97-110$.

[13] Shaked, A. and J. Sutton (1984). "Involuntary Unemployment as a Perfect Equilibrium in a Bargaining Model", Econometrica 52, 1351-64.

[14] Spagnolo, G. (2000), "Issue Linkage, Delegation, and International Policy Cooperation", mimeo. 


\begin{abstract}
APPENDIX
For Propositions 1 and 2, the structure of the proofs is as follows. Given the assumption $s>c_{1}$ and $1>c_{2}$, both surpluses are allocated under the unlinked structure. This allocation is necessarily inefficient (lies in the interior of the utility possibility set) since neither agent obtains all of the surplus preferred by that agent. As a result, at least one of the 2 agents must gain from linking. To prove that both gain (at least weakly) from linking, we show that i) no point on $\mathcal{U}_{L}$ yielding agent 2 less utility than under the unlinked structure can be a Nash bargaining solution over $\mathcal{U}_{L}$ and ii) no point yielding agent 1 less utility than under the unlinked structure can be a Nash bargaining solution over $\mathcal{U}_{L}$. To demonstrate these points, we consider the point on $\mathcal{U}_{L}$ that gives agent 2 the same utility as under the unlinked structure. We then compare the ratio of the agents utilities at this point to the slope of the utility frontier and show that this ratio is greater or equal to (the absolute value of) the slope of $\mathcal{U}_{L}$ at this point. This fact implies that the Nash bargaining solution over $\mathcal{U}_{L}$ must give agent 2 at least as much utility as the unlinked structure. Analogously, we fix the point on $\mathcal{U}_{L}$ that gives agent 1 the same utility as under the unlinked structure and compare the ratio of utilities to the slope at this point. Again we show that this ratio is less or equal to (the absolute value of) the slope of $\mathcal{U}_{L}$ at this point, implying that the Nash bargaining solution over $\mathcal{U}_{L}$ must give agent 1 at least as much utility as the unlinked structure.
\end{abstract}

As a preliminary to proving the propositions, we provide the simple algebra for determining the points in $\mathcal{U}_{L}$ that yield utility equal to that from the unlinked structure. Suppose that agent 2's utility is to be set at $U_{2}^{u}=\left[b_{2}\left(1-c_{2}\right)+s-c_{1}\right] / 2(2$ 's utility in the unlinked game). Note that, were 2 to obtain all of $S_{2}$ and 1 all of $S_{1}$, then 2's utility would be $U_{2}=b_{2}-c_{1}$. If $\left[b_{2}\left(1-c_{2}\right)+s-c_{1}\right] / 2<b_{2}-c_{1}$, then 2's unlinked utility can be achieved by an allocation that gives 1 all of $S_{1}$ and some share 
of $S_{2}$. The previous inequality is satisfied if $1-c_{2}<2-\left(s+c_{1}\right) / b_{2}$. Agent 1 's utility in this case can be found by solving for the value of $y$ that yields agent 2 his unlinked utility. This value is defined by the equation $b_{2} y-c_{1}=\left[b_{2}\left(1-c_{2}\right)+s-c_{1}\right] / 2$; or $y=\frac{1-c_{2}}{2}+\frac{s+c_{1}}{2 b_{2}}$. Substituting this value of $y$ into agent 1's utility function yields $U_{1}^{\prime}=b_{1} s+\frac{1-c_{2}}{2}-\frac{s+c_{1}}{2 b_{2}}$. Since 1 has all of $S_{1}$ and some $S_{2}$, we are on that part of the utility frontier that is to the left of the kink. The slope there is $-1 / b_{2} ; 2$ gains under the linked structure if $U_{1}^{\prime} / U_{2}^{u}>1 / b_{2}$.

If, by contrast, $1-c_{2}>2-\left(s+c_{1}\right) / b_{2}$, then agent 2 must get all of $S_{2}$ and some share of $S_{1}$ in order to achieve his unlinked utility. Now we solve for the value of $x$ that gives agent 2 this utility level. In this case the reference utility point is to the right of the kink, so that the slope of the utility frontier is $-b_{1}$.

For the case in which we want to fix agent 1's utility at his unlinked level, $U_{1}^{u}=$ $\left[b_{1}\left(s-c_{1}\right)+1-c_{2}\right] / 2$, we proceed similarly. In particular, suppose we give all of $S_{2}$ to agent 2 and all of $S_{1}$ to agent 1 . Then 1's utility is $U_{1}=s b_{1}-c_{2}$. If $\left[b_{1}\left(s-c_{1}\right)+\right.$ $\left.1-c_{2}\right] / 2<s b_{1}-c_{2}$, then we can give 1 his unlinked utility by giving 2 all of $S_{2}$ and some share of $S_{1}$. This inequality is satisfied if $s-c_{1}<2 s-\frac{1+c_{2}}{b_{1}}$. Agent 2's utility in this case can be found by solving for the value of $x$ that yields 1 his unlinked utility. This value is defined by the equation $\left[b_{1}\left(s-c_{1}\right)+1-c_{2}\right] / 2=s b_{1} x-c_{2}$; or $x=\frac{b_{1}\left(s-c_{1}\right)+1+c_{2}}{2 s b_{1}}$. Substituting this value of $x$ into 2's utility function yields $U_{2}^{\prime}=b_{2}+\frac{s-c_{1}}{2}-\frac{1+c_{2}}{2 b_{1}}$. Since 2 has all of $S_{2}$ and part of $S_{1}$, we are on the part of the utility frontier that is to the right of the kink. The slope there is $b_{1} ; 1$ gains under linking if $U_{1}^{u} / U_{2}^{\prime}<b_{1}$. The case in which $s-c_{1}>2 s-\frac{1+c_{2}}{b_{1}}$ is determined analogously.

Proof of Propositions 1 and 2:

Under separate negotiations, $U_{1}^{u}=\left[b_{1}\left(s-c_{1}\right)+1-c_{2}\right] / 2$ and $U_{2}^{u}=\left[b_{2}\left(1-c_{2}\right)+s-\right.$ $\left.c_{1}\right] / 2$. Fixing agent 2's utility at $U_{2}^{u}=\left[b_{2}\left(1-c_{2}\right)+s-c_{1}\right] / 2$, if $1-c_{2}<2-\left(s+c_{1}\right) / b_{2}$, 
then agent 1 gets all of $S_{1}$ and some share of $S_{2}$. Agent 1's utility is given by $U_{1}^{\prime}=b_{1} s+\frac{1-c_{2}}{2}+\frac{s+c_{1}}{2 b_{2}}$. Also, the slope of the utility frontier at this point is $1 / b_{2}$. From above, what we need to check is that $\frac{1}{b_{2}} \leq U_{1}^{\prime} / U_{2}^{u}=\frac{2 b_{1} s+1-c_{2}-\left(s+c_{1}\right) / b_{2}}{b_{2}\left(1-c_{2}\right)+s-c_{1}}$. This inequality is satisfied strictly if $2 s\left(b_{1} b_{2}-1\right)>0$, which it is since $b_{1}, b_{2}>1$. In this case, then, agent 2 strictly gains from linking.

If $1-c_{2}>2-\left(s+c_{1}\right) / b_{2}$, then agent 1 gets none of $S_{2}$ and only some share of $S_{1}$. Agent 1's utility is given by $U_{1}^{\prime}=\frac{b_{1}\left(s-c_{1}\right)+b_{1} b_{2}\left(1+c_{2}\right)}{2}-c_{2}$. Also, the slope of the utility frontier is $b_{1}$. Now we need to check that $b_{1} \leq U_{1}^{\prime} / U_{2}^{u}=$ $\frac{b_{1}\left(s-c_{1}\right)+b_{2} b_{1}\left(1+c_{2}\right)-2 c_{2}}{b_{2}\left(1-c_{2}\right)+s-c_{1}}$. This inequality is satisfied if $2 c_{2}\left(b_{1} b_{2}-1\right) \geq 0$. If $c_{2}>0$ then the inequality is satisfied strictly since $b_{1}, b_{2}>1$; if $c_{2}=0$ then there is strict equality and agent 2 achieves the same utility as in the unlinked case. Since at least one agent must gain from linking, in this case agent 1 gets all of the gains. Note that, in this case, the condition $1-c_{2}>2-\left(s+c_{1}\right) / b_{2}$ specializes to $s>b_{2}-c_{1}$, the condition of Proposition 2.

Now, fixing agent 1's utility at $U_{1}^{u}=\left[b_{1}\left(s-c_{1}\right)+1-c_{2}\right] / 2$, if $s-c_{1}<2 s-\frac{1+c_{2}}{b_{1}}$, then agent 2 gets all of $S_{2}$ and some share of $S_{1} \cdot{ }^{15}$ Agent 2's utility is given by $U_{2}^{\prime}=b_{2}+\frac{s-c_{1}}{2}-\frac{1+c_{2}}{2 b_{1}}$. Also, the slope of the utility frontier at this point is $b_{1}$. From above, we need to check here that $b_{1} \geq U_{1}^{u} / U_{2}^{\prime}=\frac{b_{1}\left(s-c_{1}\right)+1-c_{2}}{2 b_{2}-\left(1+c_{2}\right) / b_{1}+s-c_{1}}$. This inequality is satisfied if $2\left(b_{1} b_{2}-1\right)>0$, which it is since $b_{1}, b_{2}>1$. In this case, agent 1 strictly gains from linking.

If $s-c_{1}>2 s-\frac{1+c_{2}}{b_{1}}$, then agent 2 gets none of $S_{1}$ and only some share of $S_{2}$. In this case, 2 's utility is given by $U_{2}^{\prime}=\frac{b_{1} b_{2}\left(s+c_{1}\right)+b_{2}\left(1-c_{2}\right)}{2}-c_{1}$. Also, the slope of the utility frontier at this point is $1 / b_{2}$. From above, we need to check here again that $1 / b_{2} \geq U_{1}^{u} / U_{2}^{\prime}=\frac{b_{1}\left(s-c_{1}\right)+1-c_{2}}{b_{1} b_{2}\left(s+c_{1}\right)+b_{2}\left(1-c_{2}\right)-2 c_{1}}$. This inequality is satisfied if

${ }^{15}$ As with the case of $s=1$, if $k_{1}>2\left(1-\frac{s}{b}\right)+\frac{s k_{2}}{b}$, then it must be that this inequality is satisfied. If $k_{1}<2\left(1-\frac{s}{b}\right)+\frac{s k_{2}}{b}$, then either ineqaulity may be satisfied. 
$2 c_{1}\left(b_{1} b_{2}-1\right) \geq 0$. If $c_{1} \neq 0$, then this inequality is satisfied strictly (since $b_{1}, b_{2}>1$ ) and agent 1 is strictly better off; if $c_{1}=0$, then there is strict equality and agent 1 achieves the same utility as under the unlinked structure (agent 2 gets all of the gains). In this latter case, the condition $s-c_{1}>2 s-\frac{1+c_{2}}{b_{1}}$ specializes to $1>s b_{1}-c_{2}$, the condition of Proposition 2.

Proof of Proposition 3:

Under the assumptions of the proposition, only $S_{1}$ is allocated under the unlinked structure. The utilities of agents 1 and 2 are $U_{1}^{u}=b_{1}\left(s-c_{1}\right) / 2$ and $U_{2}^{u}=\left(s-c_{1}\right) / 2$ respectively. With $c_{2}>1$, it may not be efficient to allocate both surpluses; as a result, the point $\left(U_{1}^{u}, U_{2}^{u}\right)$ need not lie in the interior of the utility possibility set. To check this, we need only check whether there is a point on $\mathcal{U}_{L}$ that yields agent 1 utility $U_{1}^{u}$ and agent 2 utility greater than $U_{2}^{u}$.

Consider an allocation that gives all of $S_{1}$ and a share $1-y^{\prime}$ of $S_{2}$ to agent 1 and that yields 1 utility of $U_{1}^{u}$. The value of $y^{\prime}$ under this allocation is the solution to the equation $b_{1} s+1-c_{2}-y^{\prime}=b_{1}\left(s-c_{1}\right) / 2$ and is given by $y^{\prime}=b_{1}\left(s+c_{1}\right) / 2+1-c_{2}$. If $y^{\prime} \in(0,1)$, then this allocation gives the point on $\mathcal{U}_{L}$ yielding agent 1 the same utility as under the unlinked structure. The value of $y^{\prime}$ lies on $(0,1)$ if $s+2 / b_{1}>$ $2 c_{2} / b_{1}-c_{1}>s$. The second inequality is satisfied by our assumption on $s$; the assumption that $c_{1}\left(b_{1}-1 / b_{2}\right)<c_{2}-1<.5\left(s+c_{1}\right)\left(b_{1}-1 / b_{2}\right)$ implies that the first inequality is satisfied. Agent 2's utility at this point is $U_{2}^{\prime}=b_{2} y^{\prime}-c_{1}$ and this utility is larger than $U_{2}^{u}$ as long as $\left(1-c_{2}\right)+.5\left(s+c_{1}\right)\left(b_{1}-1 / b_{2}\right)>0$. Therefore, under the conditions of the proposition, the point $\left(U_{1}^{u}, U_{2}^{u}\right)$ lies in the in the interior of the utility set and so the linked structure must make at least one agent better off.

To conclude the proof, we need only show that agent 1 is made worse off. Since the point on $\mathcal{U}_{L}$ yielding 1 the same utility as under the unlinked structure lies to the left of the kink, 1 is worse off if $1 / b_{2}<U_{1}^{u} / U_{2}^{\prime}$. This inequality is satisfied as long as $1-c_{2}+c_{1}\left(b_{1}-1 / b_{2}\right)<0$. 
Figure 1: Two symmetric games; player i has a comparative interest in game $i$

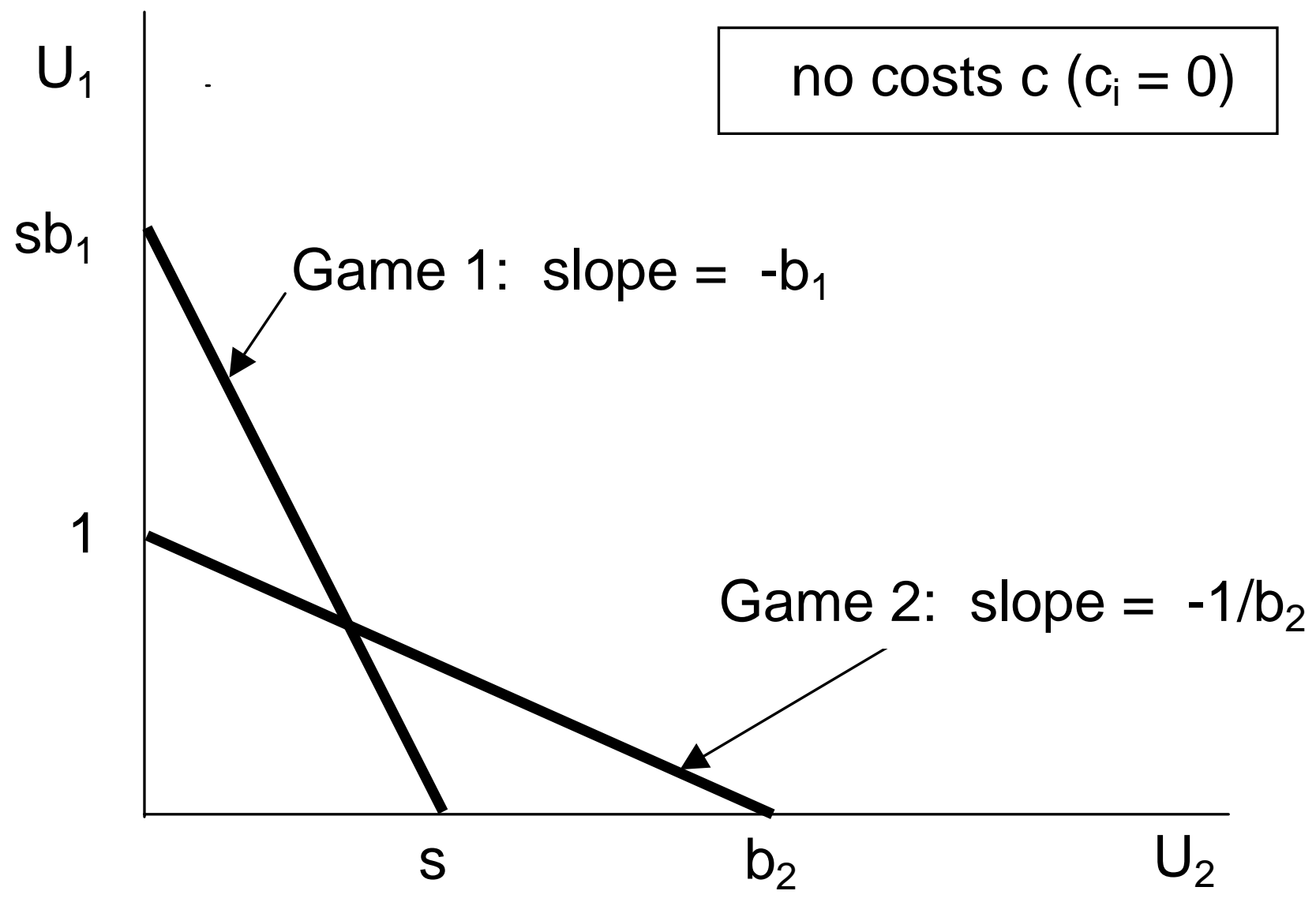

Notation: $U_{1}=s b_{1}-b_{1} U_{2}$ game 1

$$
U_{2}=b_{2}-b_{2} U_{1} \text { game } 2
$$


Figure 2: Two symmetric games; player $\mathrm{i}$ has a comparative interest in game $i$

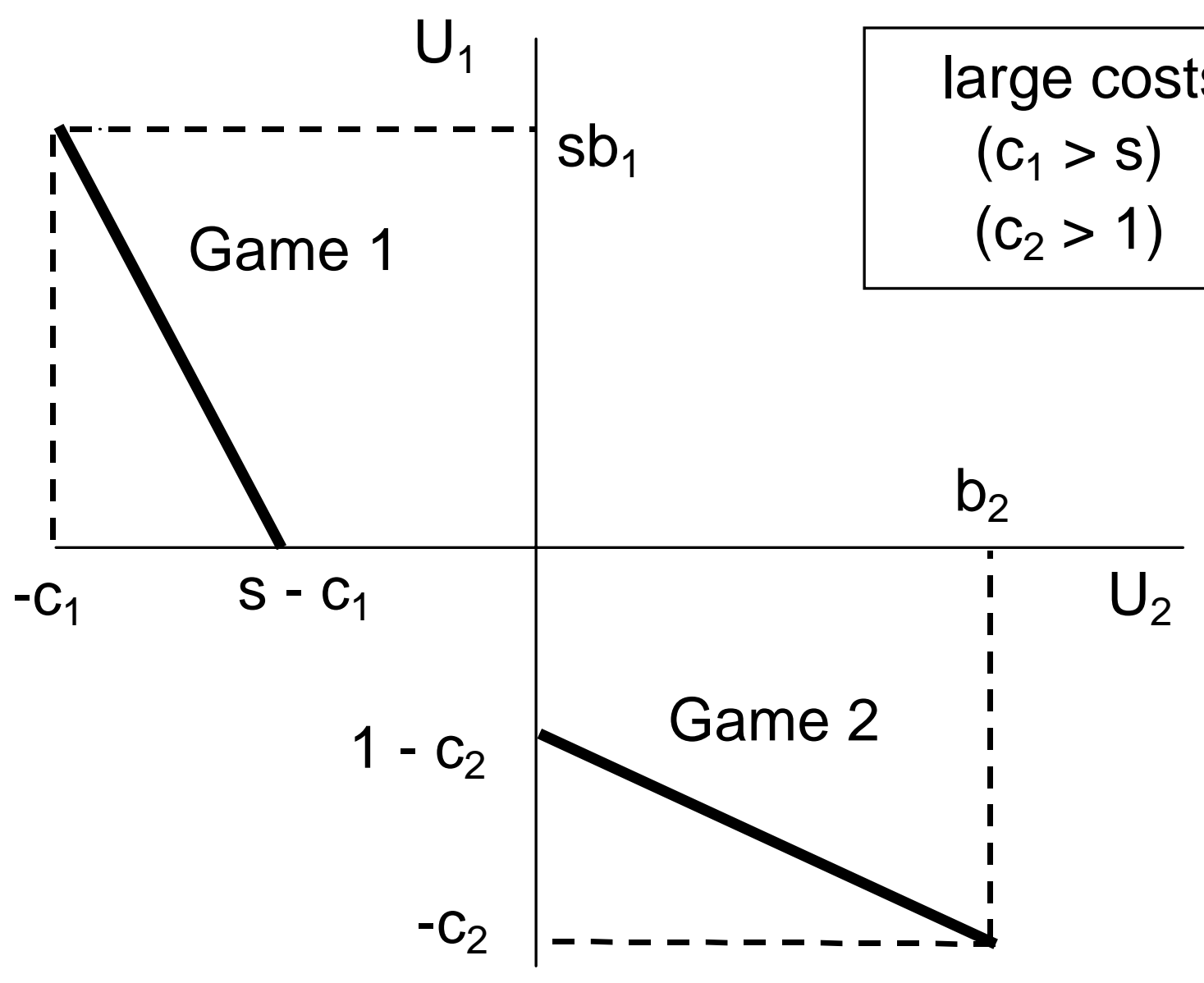

Notation: $U_{1}=s b_{1}-b_{1}\left(U_{2}+c_{1}\right)$

$$
\mathrm{U}_{2}=\mathrm{b}_{2}-\mathrm{b}_{2}\left(\mathrm{U}_{1}+\mathrm{c}_{2}\right)
$$


Figure 3: Two symmetric games: player i receives strictly positive payoffs in both games

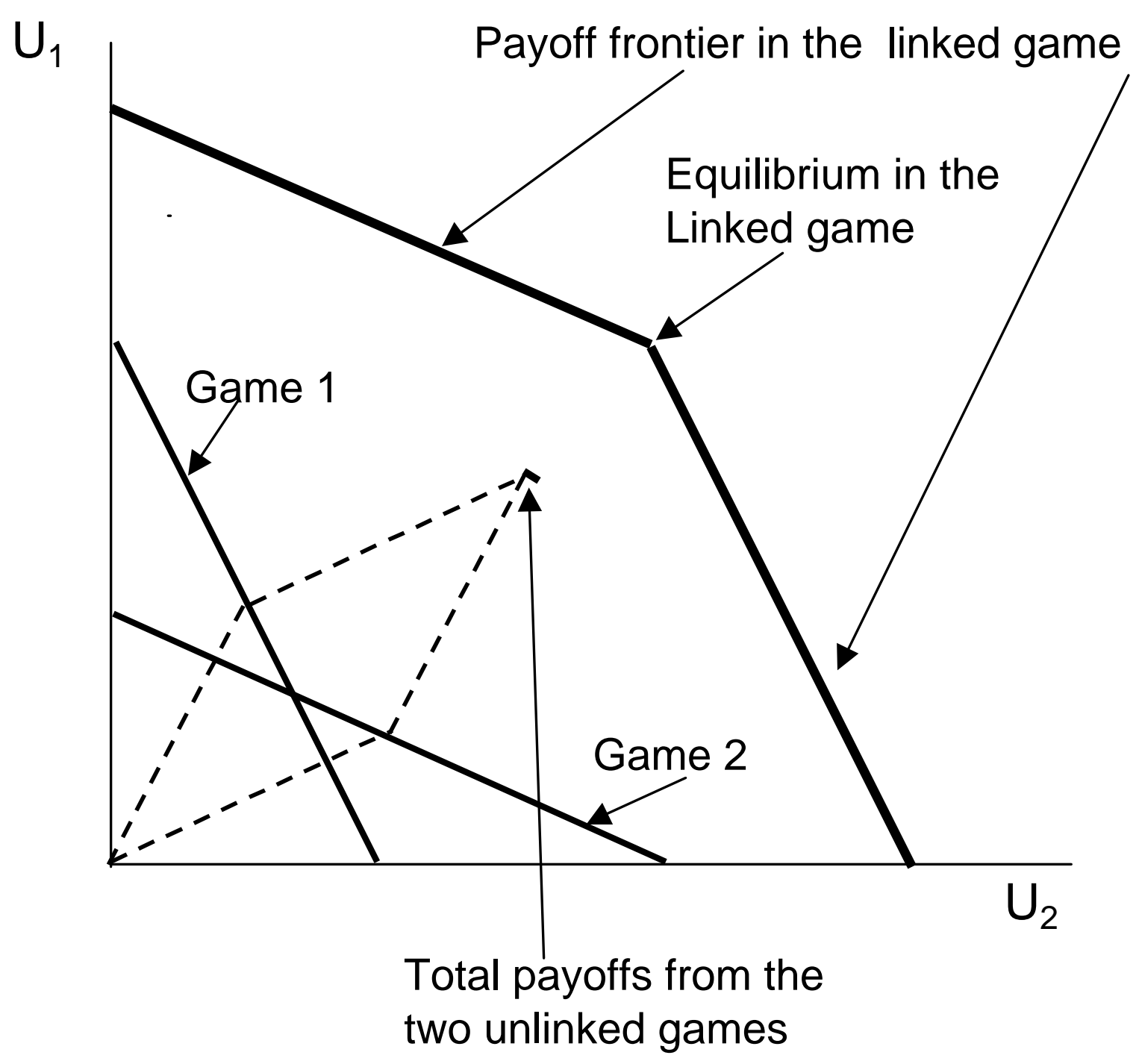


Figure 4: Two symmetric games: linking can be Pareto improving even if a player receives a negative payoff on one issue

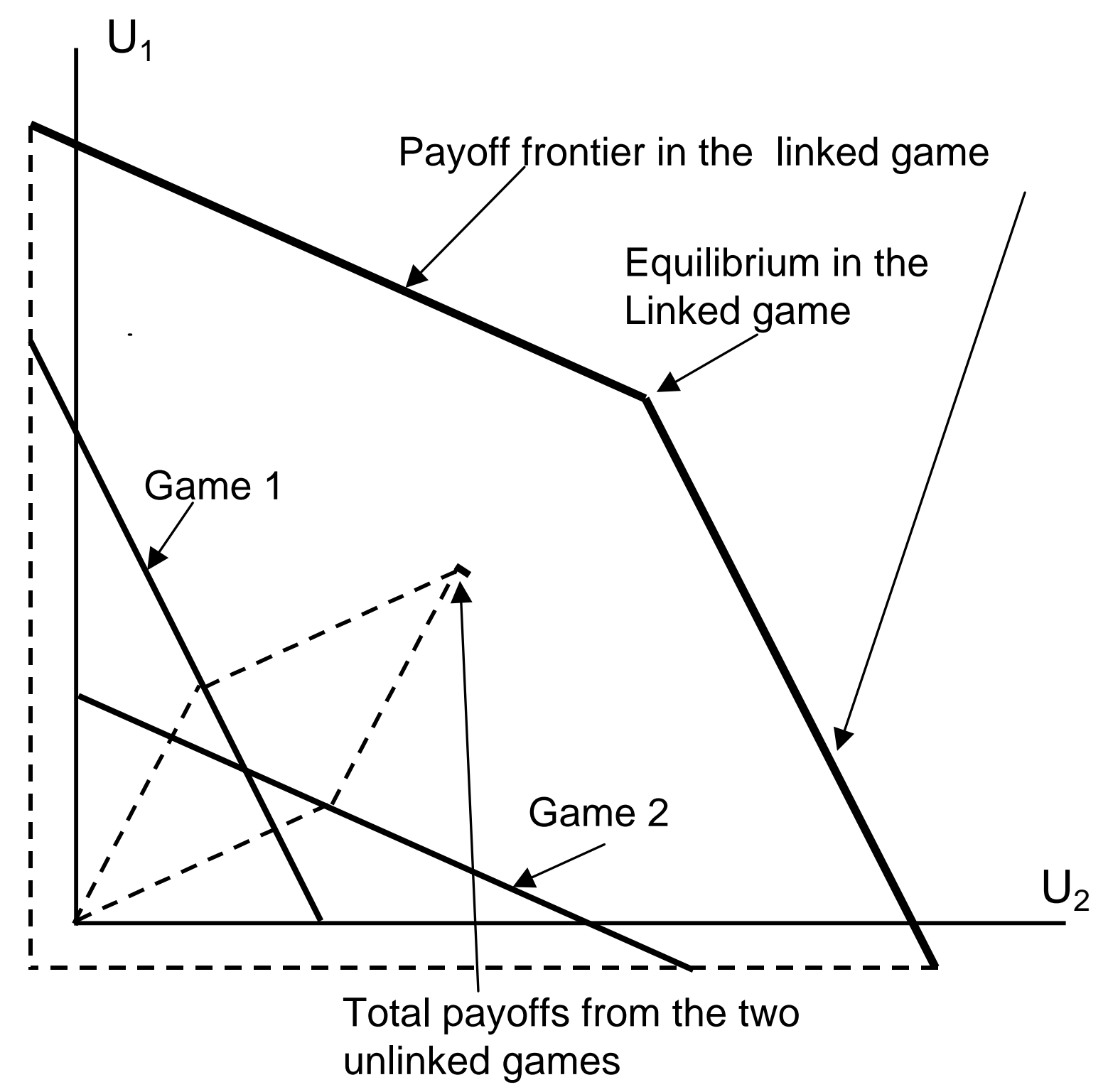

N.B. Compared to Figure 2, the total payoffs from the two unliked games is the same, but the payoffs in the linked game are larger. Here it pays to take a negative payoff from one issue in order to gain more on your comparative-interest issue 
Figure 5: When is linking not Pareto improving?
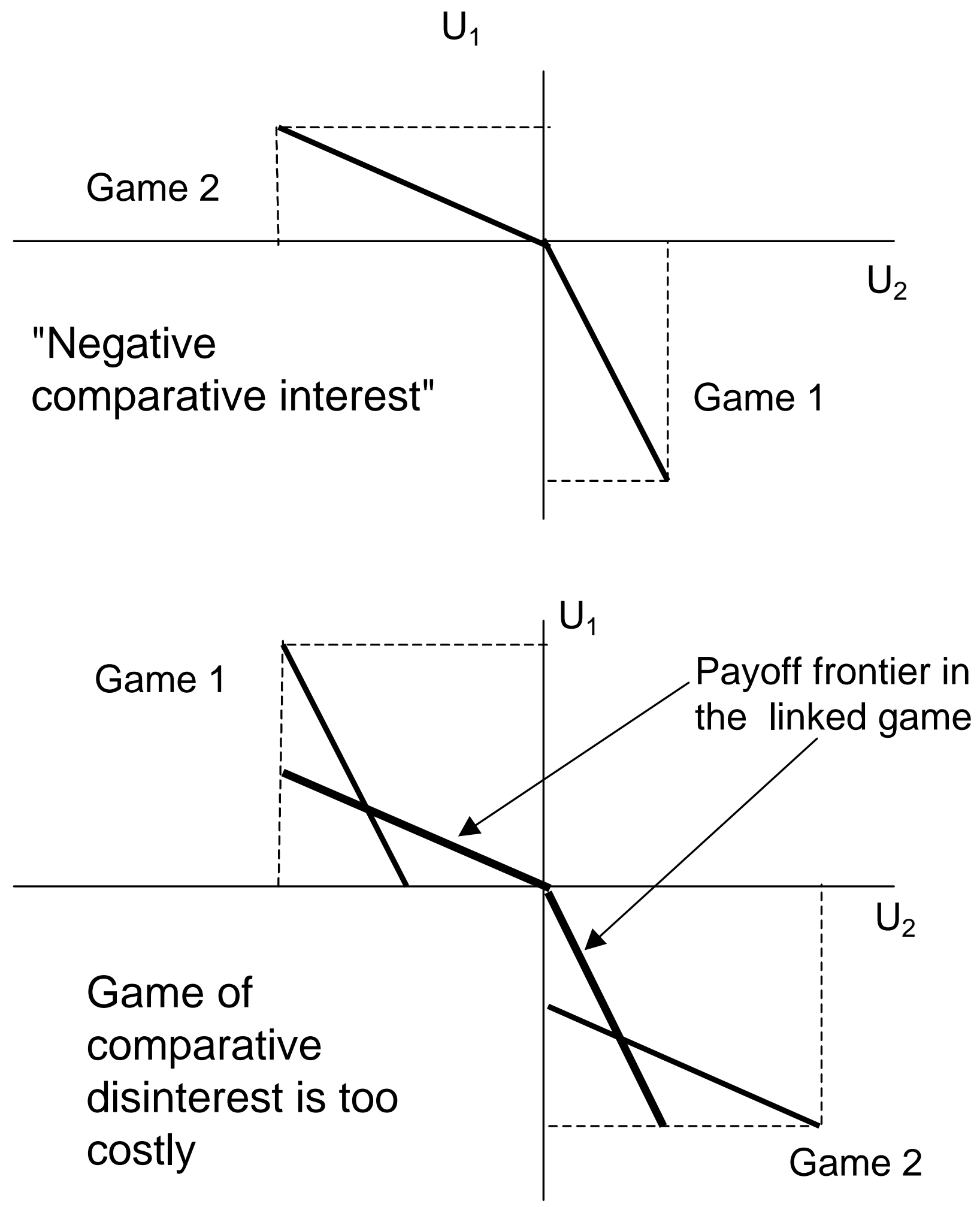
Figure 6: Geometric interpretation and proof of Proposition 1

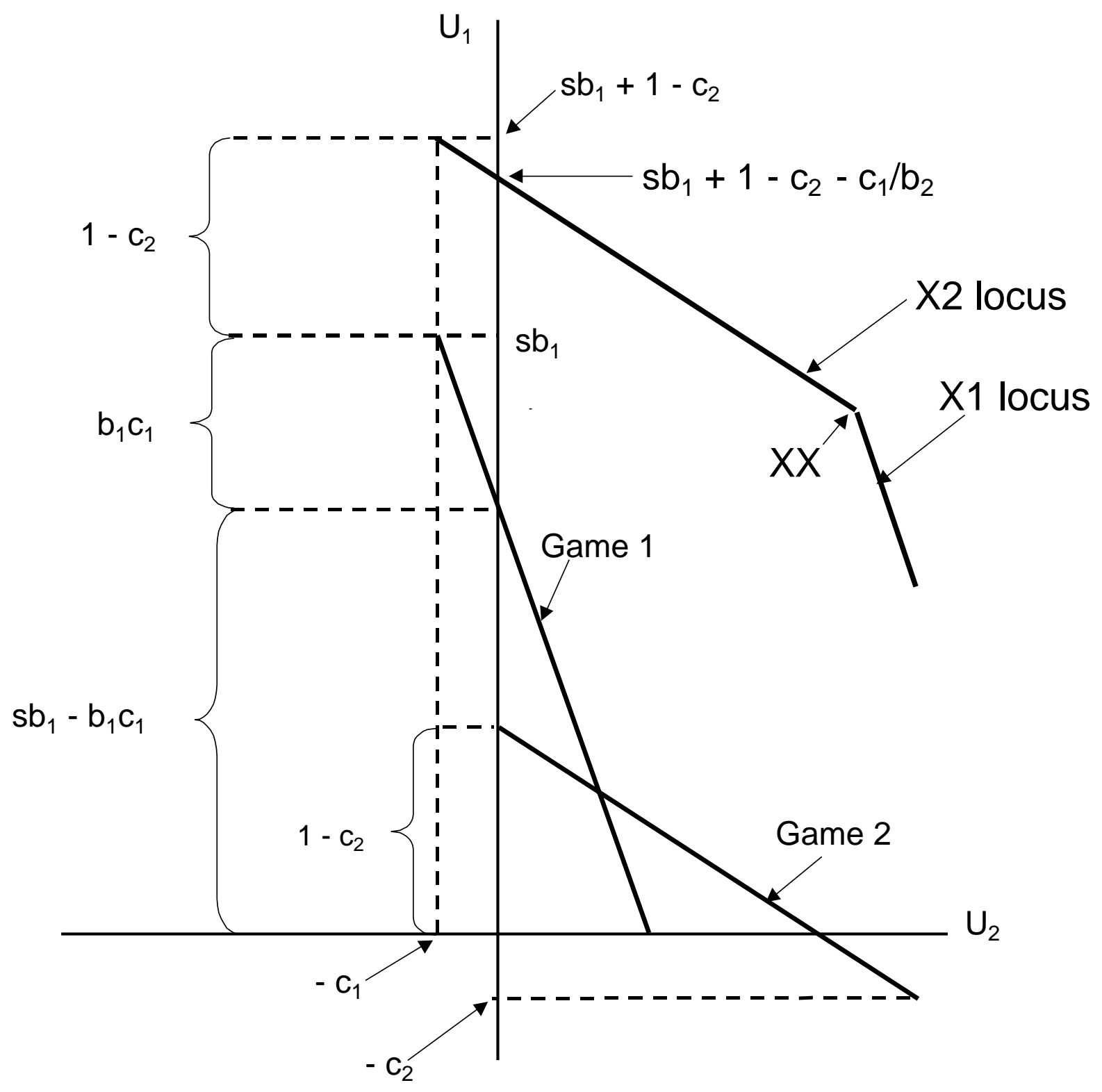

Minimum payoff to player 1 in

$\mathrm{U}_{1}^{*}=\left[\mathrm{sb}_{1}+1-\mathrm{c}_{2}-\mathrm{c}_{1} / \mathrm{b}_{2}\right] / 2$ the linked game:

Sum of payoffs to player 1

$\mathrm{U}_{1}^{\prime}=\left[\mathrm{sb}_{1}+1-\mathrm{c}_{2}-\mathrm{c}_{1} \mathrm{~b}_{1}\right] / 2$ in the two unlinked games

Minimum Difference

$\mathrm{U}_{1}{ }^{*}-\mathrm{U}_{1}{ }^{\prime}=\mathrm{c}_{1}\left(\mathrm{~b}_{1}-1 / \mathrm{b}_{2}\right) / 2>=0$ 
Figure 7: Game 1 is "small" if the game 1 triangle fits inside the game 2 triangle

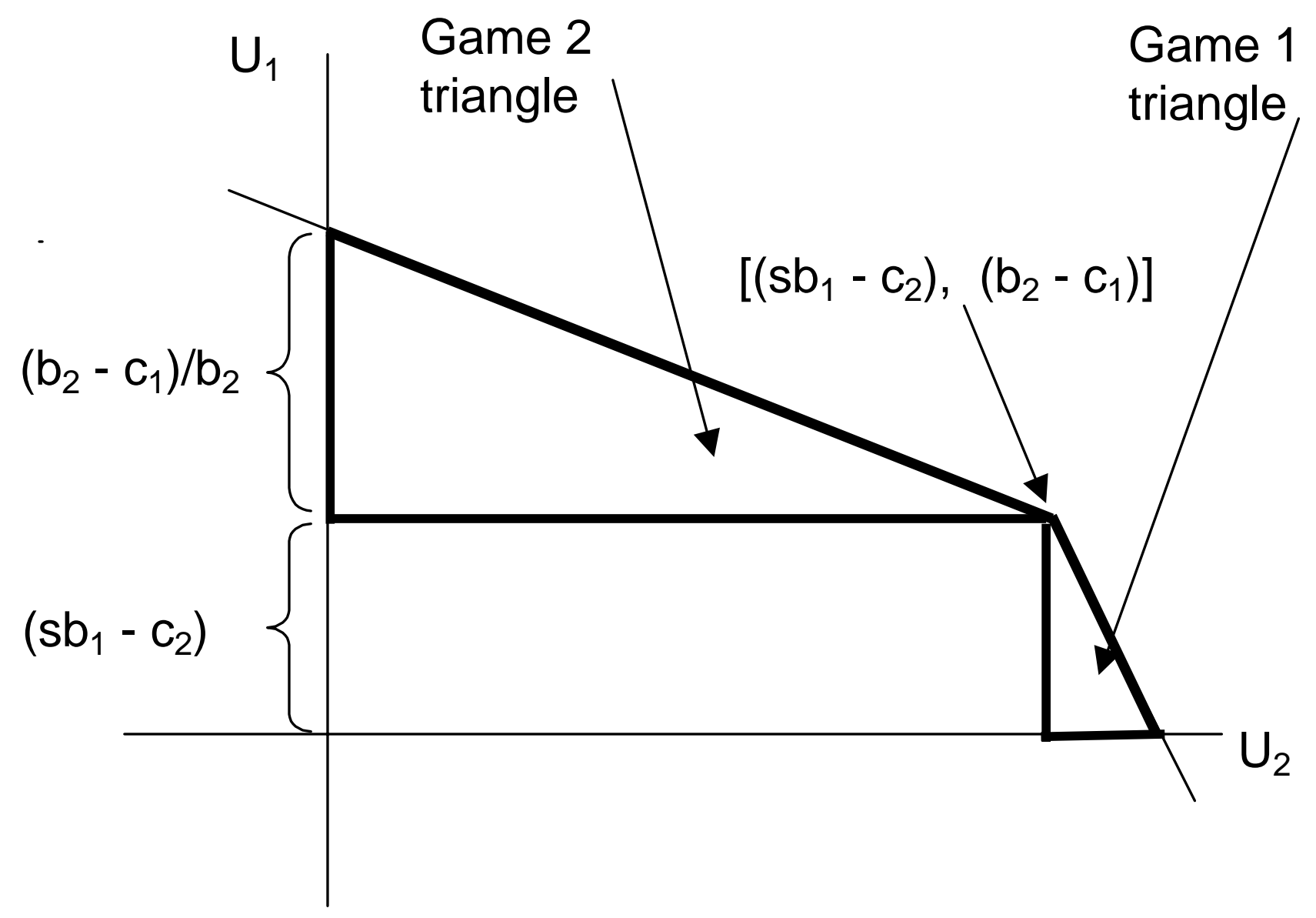

"smallness" is satisfied for game 1 here if: $\left(\mathrm{sb}_{1}-\mathrm{c}_{2}\right)<\left(\mathrm{b}_{2}-\mathrm{c}_{1}\right) / \mathrm{b}_{2}$ 
Figure 8: Game 1 is small. All gains from linkage captured by player 2

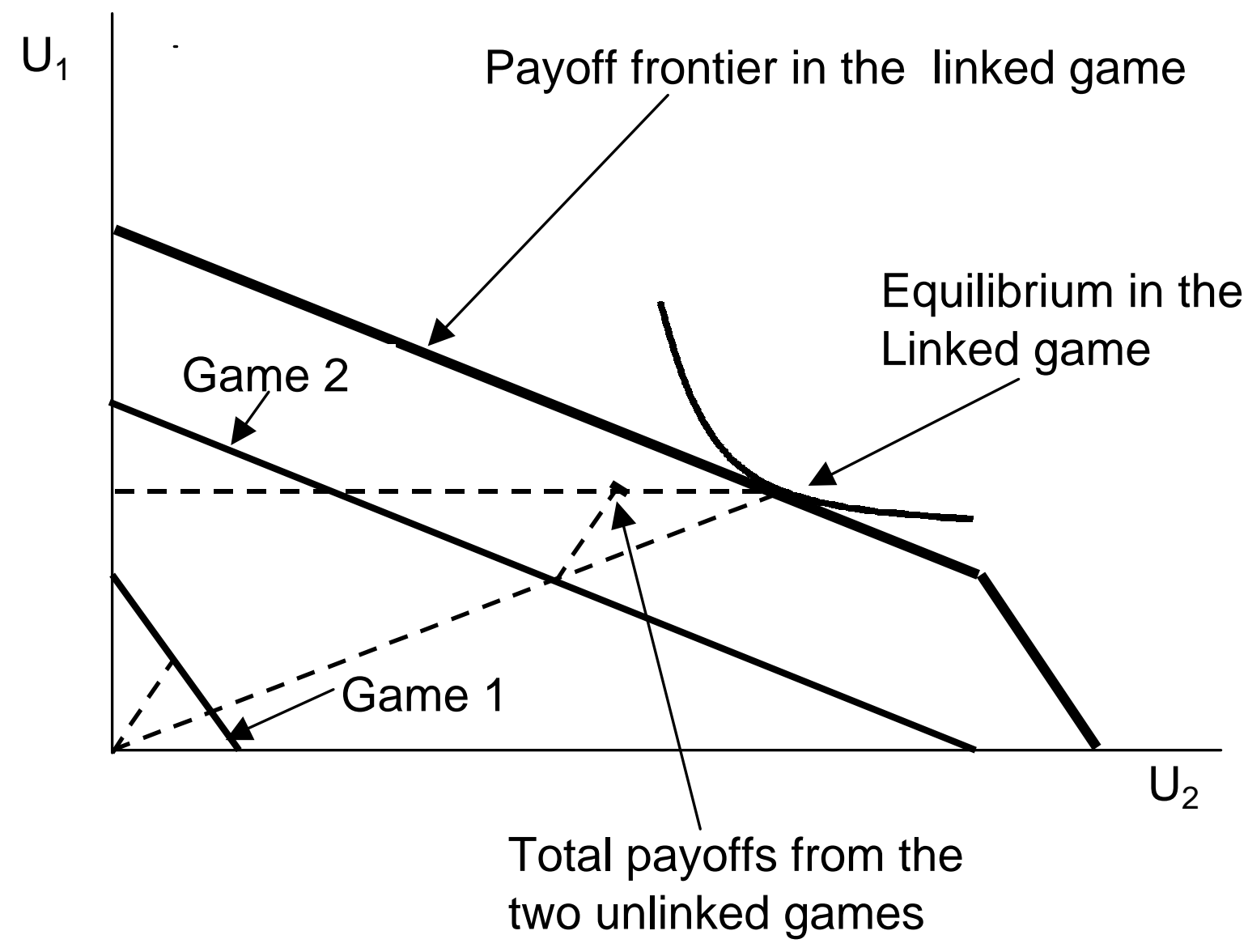


Figure 9: A strictly negative payoff for $U_{1}$ in game 2 is not sufficient for linking worsen 1 's welfare

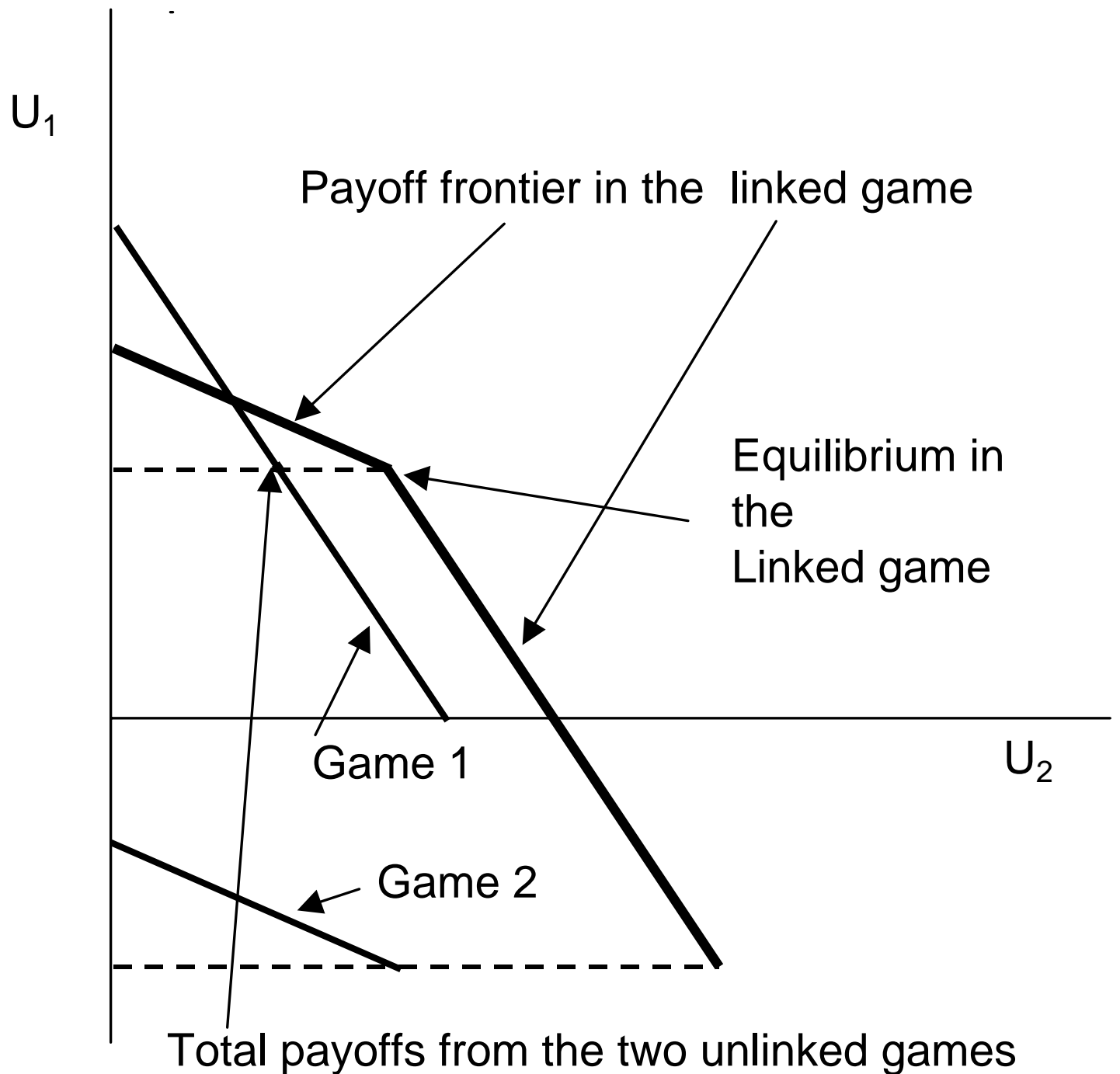
(player 1 refuses to play game 2) 
Figure 10: Linking worsens player 1's welfare (a strictly negative payoff for $U_{1}$ in game 2 seems to be a necessary condition)

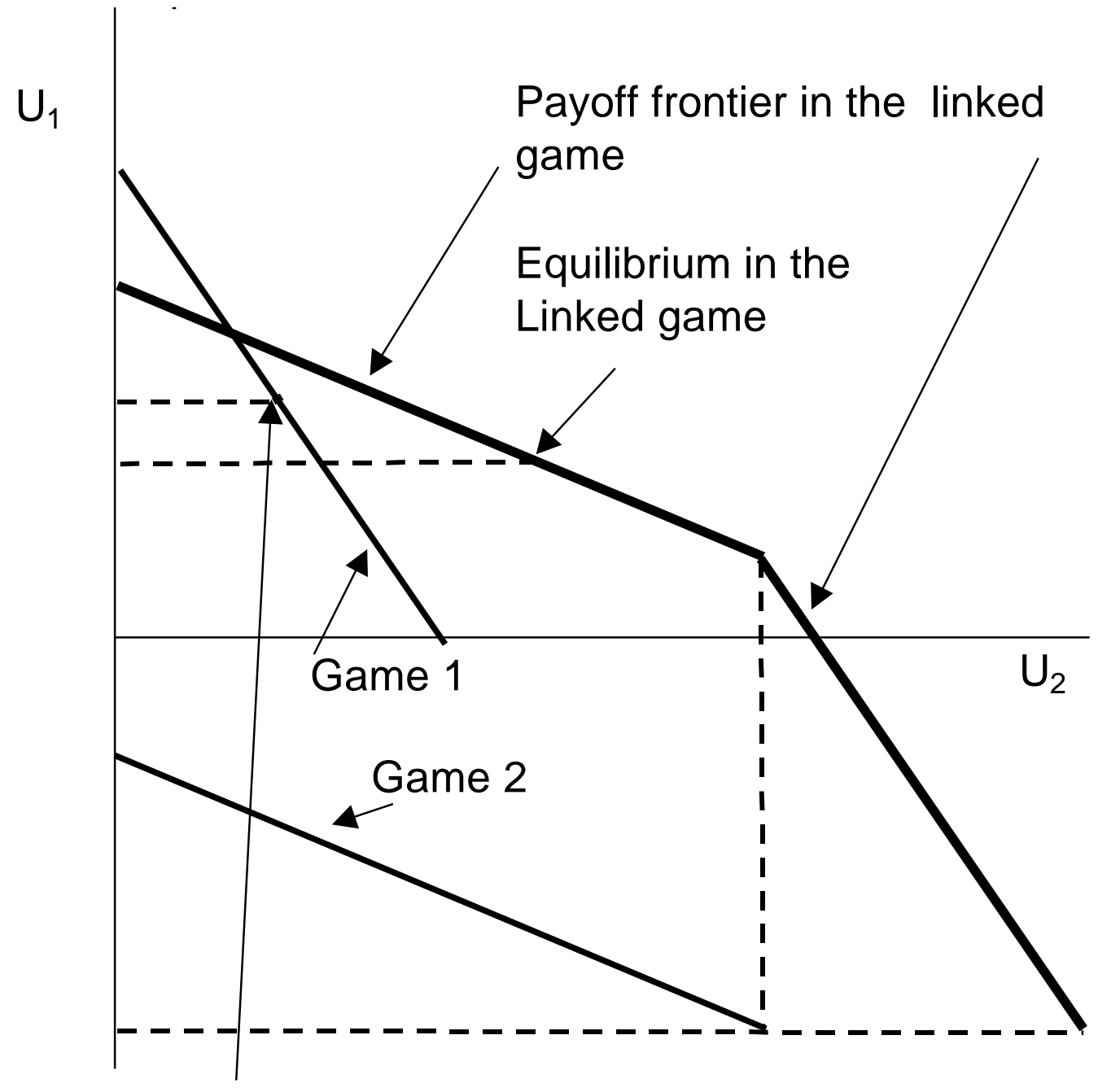

Total payoffs from the two unlinked games (player 1 refuses to play game 2) 
Figure 11: Outcomes in the numerical general-equilibrium model: Game 1 - environment, Game 2 - trade

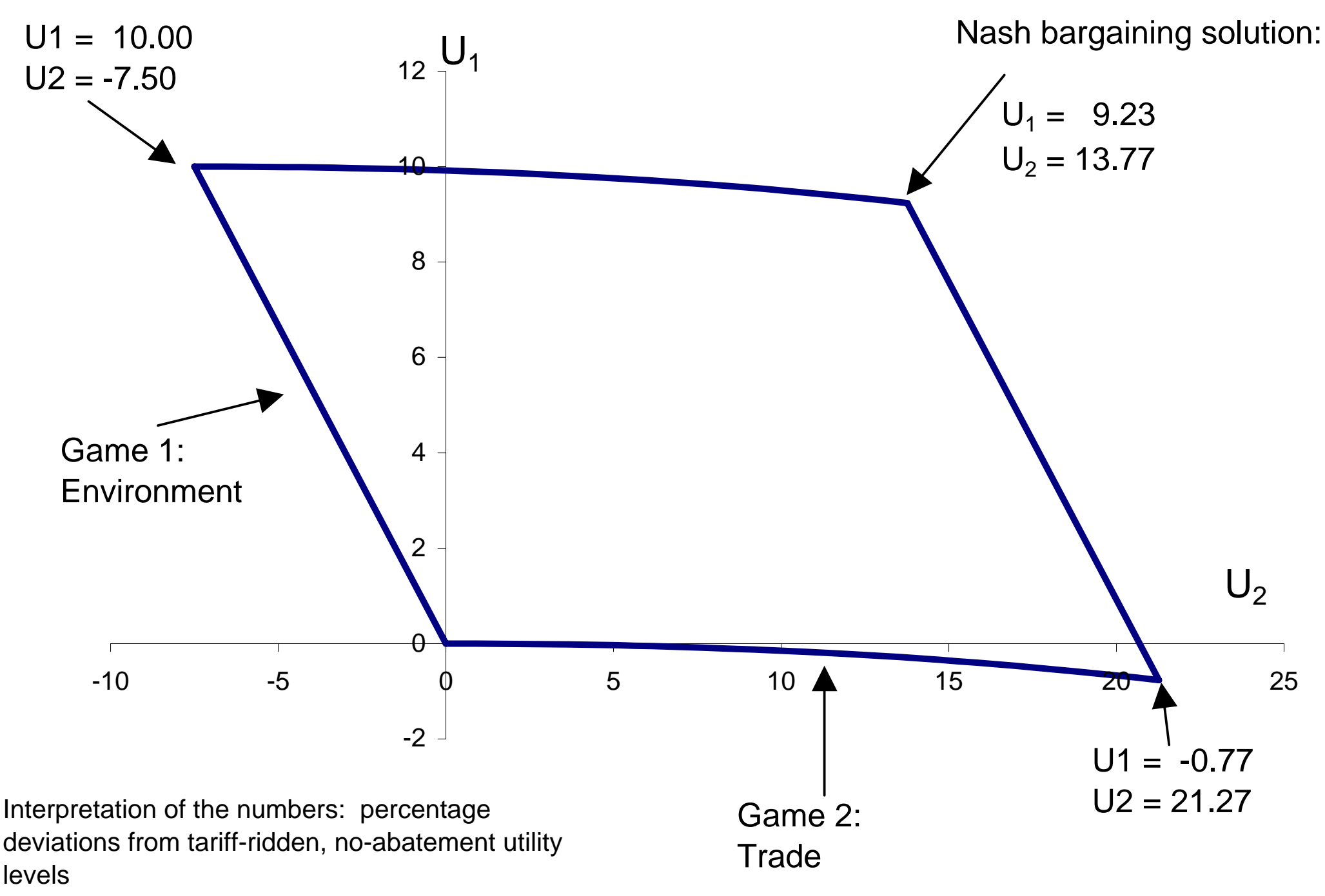

